\title{
Sur la pluralité des monnaies publiques dans les fédérations
}

Une approche de ses conditions de viabilité à partir de l'expérience argentine récente

Bruno Théret et Miguel Zanabria

\section{(2) OpenEdition \\ Journals \\ Édition électronique \\ URL : http://journals.openedition.org/ei/295 \\ DOI : 10.4000/ei.295 \\ ISSN : 2553-1891 \\ Éditeur}

Association Économie et Institutions

Édition imprimée

Date de publication : 30 octobre 2007

Pagination : 9-66

ISSN : 1775-2329

Référence électronique

Bruno Théret et Miguel Zanabria, «Sur la pluralité des monnaies publiques dans les fédérations », Économie et institutions [En ligne], 10-11 | 2007, mis en ligne le 31 janvier 2013, consulté le 19 avril 2019. URL : http://journals.openedition.org/ei/295 ; DOI : 10.4000/ei.295 
Sur la pluralité des monnaies publiques dans les fédérations. Une approche de ses conditions de viabilité à partir de l'expérience argentine récente

\author{
Bruno Théret (CNRS, IRISES) et Miguel Zanabria (Universidad \\ Nacional de Quilmes)
}

\title{
Introduction
}

Cet article vise à esquisser les principes de ce qui pourrait s'appeler un fédéralisme monétaire viable. Il part de l'idée suivante. Les conceptions prévalentes de la monnaie à une époque donnée, qui fournissent les principes de la régulation monétaire en vigueur à cette époque, dépendent de la manière dont le lien social et donc l'ordre politique et la souveraineté sont eux-mêmes conçus. Bien que la souveraineté monétaire et la souveraineté politique ne doivent pas être confondues, la stabilité de l'une comme de l'autre implique néanmoins qu'elles entretiennent des relations de cohérence entre elles. S'agissant par l'une comme par l'autre de lier entre eux des individus et de constituer un groupement humain à vocation perpétuelle sur un espace commun, elles doivent prendre des formes institutionnelles qui se renforcent les unes les autres ou, pour le moins, ne sont pas en contradiction entre elles. Ainsi, sauf à ce que la confiance dans la monnaie soit menacée et/ou que l'ordre politique soit déstabilisé, les principes d'organisation de la monnaie doivent être cohérents avec ceux qui fondent la communauté politique. Cela implique que le régime de monnayage (le mode de fixation de l'unité de compte et d'émission, mise en circulation et destruction des instruments de paiements) reproduise dans son domaine propre les valeurs éthiques qui fondent l'ordre politique.

Dans cette perspective, la question de la souveraineté monétaire ne saurait se poser de la même façon dans un système politique fédéral et dans un État unitaire. Il faut donc, lorsqu'on étudie la monnaie dans des systèmes politiques organisés selon les principes du fédéralisme, prendre en compte les implications de la spécificité de ce type d'organisation politique sur le régime monétaire. C'est cette question qui est explorée ici à partir du cas argentin et de la présence récurrente dans ce pays, tout au long de son histoire, de monnaies fiscales provinciales manuelles. De telles monnaies sont le plus souvent considérées - y-compris par les économistes - comme des monnaies de crise, des substituts temporaires à des défaillances momentanées des pouvoirs monétaires qu'il s'agit de résorber dès 
lors que semble se dessiner un "retour à la normale ", retour à la normalité de l'unicité monétaire qui, quant à elle, ne saurait être mise en question ${ }^{1}$. Vu la récurrence de leur apparition tout au long de l'histoire argentine, il semble pourtant nécessaire de s'interroger sur ces expériences monétaires en ne les posant pas a priori comme des anomalies, et en examinant dans quelle mesure elles ne révèlent pas plutôt un problème structurel inhérent à certains contextes institutionnels et politiques, compte tenu de conceptions de la régulation monétaire inadéquates à ces contextes. On peut en effet tout aussi bien y voir des innovations annonçant l'avenir, mais en permanence contrariées par des rapports de force politiques défavorables. Rappelons à ce propos le sort intellectuel réservé aux expériences récurrentes d'émission de papier-monnaie dans les crises monétaires dès le XVIème et XVIlème siècle en Europe, dans des contextes où la normalité monétaire était celle des monnaies métalliques ; elles étaient condamnées et éliminées de la circulation une fois la crise passée. Pourtant ces monnaies de papier, fiat monnaie, ont fini par s'imposer et devenir la normalité tandis que le métal est devenu un référentiel monétaire désuet.

Dans cet article, pour explorer cette hypothèse, nous partons d'un cadre théorique, fondé à la fois dans la logique et l'histoire, dans lequel la pluralité monétaire est posée comme l'état normal des systèmes monétaires des sociétés modernes, et non comme un de leurs états critiques (Théret, 2007 ; Servet, Théret et Yildirim, 2008 ; Théret, 2008a). Dans ce cadre, la monnaie n'est pas réduite à une fonction de facilitation ou de stimulation des échanges marchands,

1 En Argentine même, seul Julio Olivera, économiste jouissant d'un grand prestique intellectuel dans son pays et qui est également reconnu au niveau international notamment pour ses travaux concernant la monnaie, s'est interrogé sur les implications du fédéralisme pour la construction du système monétaire argentin. Ses quelques écrits sur cette question (Olivera, 1981, 1989 et 1992) sont cependant peu connus, y-compris en Argentine, car ils ont été publiés dans des médias régionaux et de faible diffusion, au contraire de ses autres écrits. Olivera montre qu'en dépit de la constitution fédérale de l'Argentine et des dispositions décentralisatrices en matière monétaire qu'elle contient, la banque centrale argentine "fonctionne comme un organisme totalement centralisé " (Olivera 1992, p. 14). Elle ne dispose pas d'agences et de succursales à l'extérieur de Buenos Aires, en dépit de sa charte organique qui lui permet, voire l'oblige à en ouvrir dans l'intérieur du pays. Il qualifie cette situation de "centralisation absolue " qui " ne concorde pas avec le système constitutionnel "du pays (ibid., p. 15). Pour lui, "la taille du pays et l'amplitude de ses différences interrégionales justifient une décentralisation administrative " (ibid., p. 16), ce qui implique une réforme monétaire profonde en direction d'une constitution monétaire à l'allemande, dotant les provinces d'un réel pouvoir monétaire susceptible de promouvoir leur développement économique à partir de leurs situations économiques propres.

10 Economie et Institutions - n ${ }^{\circ} 10$ et $11-1$ er $\& 2$ e semestre 2007 
mais est aussi, en tant qu'opérateur d'appartenance sociale, destinée à assurer la reproduction de l'ordre politique et de son économie de prélèvement-redistribution (Théret, 1998). Dans cette perspective, la Banque centrale n'est pas seulement l'émetteur actif et/ou passif d'une base monétaire fonctionnellement indifférenciée, c'est aussi et surtout une institution régulatrice réglant la concurrencecomplémentarité entre émissions de monnaies publiques et privées, lesquelles renvoient aux logiques économiques contradictoires propres respectivement à la sphère étatique et à la sphère capitaliste marchande. La crise monétaire des années 2001-2003 en Argentine appelle une telle perspective en conduisant à réorienter le regard sur les monnaies émises pour des raisons politiques par des pouvoirs publics, nationaux mais aussi éventuellement régionaux, monnaies fiscales oubliées voire déniées par la théorie économique orthodoxe, $\mathrm{y}$-compris lorsque ces monnaies fiscales prennent comme en Argentine une forme manuelle (billets) particulièrement visible.

Dans une première partie de l'article, nous présentons le cadre théorique et historique qui justifie qu'on s'intéresse à ces expériences d'émission de monnaies fiscales provinciales. Dans la seconde et la troisième partie, nous analysons ces expériences. Dans la seconde partie, alimentée par des enquêtes de terrain, nous mettons d'abord en regard l'une de l'autre les expériences du patacon, émis par la Province de Buenos Aires, et celle du federal, monnaie émise quant à elle par la Province de l'Entre Rios ${ }^{2}$. Dans la troisième partie, afin de dégager des conditions générales de viabilité de ce type de monnaies, nous élargissons notre point de vue à trois autres provinces (Cordoba, Corrientes et Santa Fé qui n'a pas émis de monnaie). Il s'agit alors de faire ressortir, sur la base de données statistiques, des régularités concernant diverses variables économiques, politiques et symboliques qui semblent pertinentes pour comprendre et expliquer les conditions de succès ou d'échec de ces expériences.

\section{Cadre théorique et historique}

Toute société dotée de monnaie peut être considérée comme un tissu de dettes/créances qui, bien que de natures ou origines diverses, sont toujours engendrées par des transferts de possession et/ou de propriété sur des biens réels ou symboliques. Ces dettes/créances proviennent de transactions aussi diverses que des échanges de type marchand, des prélèvements centralisés et

2 Nous écrivons province avec une minuscule lorsqu'il s'agit d'une province au sens géographique, et Province avec une majuscule lorsqu'il s'agit des institutions gouvernementales et administratives du territoire provincial.

Economie et Institutions $-\mathrm{n}^{\circ} 10$ et $11-1$ er $\& 2$ e semestre 2007 
redistribués, ou encore des dons entre humains et entre humains et divinités ou autres autorités symboliques. Par delà son rôle dans les diverses sphères transactionnelles où elle permet les transferts de dettes et la reproduction corrélative des relations sociales qui structurent ces sphères, la monnaie est le médium qui donne une forme mesurable et quantifiée à cet ensemble a priori hétérogène de relations sociales constitutives de la société considérée; par sa médiation, les interdépendances sociales qui prennent la forme d'obligations et de droits réciproques entre les sociétaires et entre ceux-ci et les organisations collectives représentatives du tout de la société sont traduites en termes de dettes et de créances homogénéisées.

La monnaie apparaît ainsi d'abord comme unité de compte, ce par quoi elle constitue une première forme de représentation symbolique unitaire d'une totalité sociale. Mais la monnaie est aussi ce qui permet de faire circuler dettes et créances entre les membres de la société, lui donnant par là un second type d'unité dans le cours de sa reproduction dans le temps, une unité dynamique. Elle est alors moyen de paiement des dettes, que celles-ci prennent la forme de dettes remboursables par le débiteur dans le cours de son existence ou de rentes viagères et perpétuelles non remboursables (les impôts par exemple). La monnaie qui circule dans la chaîne des paiements est ce qui permet que les dettes soient honorées et donc relancées dans un cycle qui constitue le cœur de la reproduction sociale. Finalement, en tant qu'elle est à la fois unité de compte et moyen de paiement, la monnaie est donc un lien social clef, un opérateur de totalisation unifiant le système des dettes et le reproduisant en dynamique. Elle représente symboliquement une société en tant que tout, mais c'est une représentation active qui participe à la construction et à la reproduction de ce tout.

Cette conception de la monnaie comme unité de compte et moyen de paiement des dettes a trois conséquences théoriques fondamentales pour ce qui nous intéresse ici. Tout d'abord, la monnaie ne peut plus être pensée exclusivement comme une invention des sociétés marchandes modernes comme le voudrait la fable du troc; elle est un "phénomène" social universel, un invariant anthropologique comme le langage dont elle est une forme spéciale. Ensuite, du fait que les sociétés capitalistes sont des sociétés centralisées et dotées d'un Etat, les formes de dette qui lient les individus au tout de la société et à ses représentants y perdurent. Elles y prennent notamment la forme de la dette sociale, pour l'essentiel jusqu'alors une dette publique représentée par la fiscalité (obligation vis-à-vis de l'Etat) et/ou sa contrepartie la dépense de protection sociale (obligation de l'Etat vis-à-vis de tout citoyen). Enfin, troisième conséquence, dans la relation de la monnaie à la 
dette sociale résident les fondements du lien entre monnaie et souveraineté.

\subsection{Souveraineté politique et souveraineté monétaire}

L'expression souveraineté monétaire renvoie dans les sociétés modernes à une souveraineté sur la monnaie plus qu'à une souveraineté de la monnaie, l'argent n'étant plus, en dépit du sens commun, l'expression d'une autorité représentant la valeur ultime de la société, mais seulement un élément non exclusif du pouvoir souverain. En effet, la monnaie ne vaut plus - ou alors on parle de corruption - pour évaluer les biens supérieurs que sont la vie humaine et les droits politiques des membres du corps social. Dans la hiérarchie de valeur qui est au principe de la totalisation sociale, l'argent, du fait de sa banalisation économique et de son caractère anonyme et omniprésent, est en position inférieure. En effet, son usage tend à devenir de plus en plus marginal dans l'évaluation des échanges sociaux hiérarchiquement supérieurs en valeur qui sont le propre des sphères domestique et politique (échanges matrimoniaux, compensation des meurtres et autres crimes, élections des représentants et dirigeants). Ainsi dans l'ordre politique, l'équation qui s'impose comme norme est qu'une personne égale une personne, indépendamment de leurs richesses respectives. Ainsi l'argent, la monnaie spécifique au capitalisme de marché " ne pourra jamais être un médiateur adéquat " dans les "relations inter-humaines qui recherchent par essence la durée " (Simmel, 1987, p. 473). Cela signifie que, par delà les prétentions dont il peut être porteur, l'argent a au fond perdu la capacité de symboliser la valeur supérieure qu'est l'éternité (ce dont témoigne l'avènement de la monnaie de pur crédit dont l'avenir est lié à des croyances contingentes). Et si la monnaie peut encore représenter le tout social (entre autres à travers la construction politico-symbolique du PIB national), c'est au prix de ce qu'André Orléan (2007) appelle sa "captation " fiscale par l'Etat et de son immersion dans un système " national" qui se veut homogène de comptes et de paiements, système où la monnaie marchande doit cohabiter avec d'autres monnaies - fiscales et sociales - qui, quant à elles, médiatisent des échanges sociaux qui ne sont pas réglés selon les principes de l'accumulation de capital économique.

Cela dit, pour éclaircir la relation entre souveraineté et monnaie, il ne suffit pas de distinguer entre souveraineté de la monnaie et souveraineté (du pouvoir politique) sur la monnaie. Car, les crises monétaires le montrent, cette relation est également différenciée en fonction des conceptions prédominantes et des formes institutionnelles effectives que prend la souveraineté politique (Cités, 
Empires, Etats unitaires, Fédérations) (Théret, 2008b). Ainsi, les diverses formes de la souveraineté politique par lesquelles les sociétés se construisent comme totalités doivent être mises en relation avec les formes monétaires qui y prévalent simultanément. L'Argentine, notre terrain d'enquête dans cet article, est une fédération; son ordre politique n'est pas organisé sur le modèle de l'Etat unitaire et la souveraineté politique y prend une forme spécifique. La forme fédérale de la souveraineté est fondée sur une séparation entre deux niveaux hiérarchisés en valeur, le niveau supérieur de l'autorité et celui subordonné du pouvoir. Dans un système politique fédéral, en effet, il n'existe pas de pouvoir souverain au sens "moderne" (pouvoir supérieur à tous les autres dans tous les champs de compétence politique), puisque le pouvoir est partagé entre l'Etat fédéral et les entités fédérées et qu'il n'y a donc pas d'omnicompétence. En revanche il y a bien une autorité souveraine à laquelle doivent se soumettre, pour que la fédération perdure, les divers pouvoirs politiques qui se disputent la prééminence ; cette autorité est celle du Grand Texte Constitutionnel instituant le Pacte fédéral et soutenu par une Cour suprême en position d'autorité pour l'interpréter en cas de conflit entre les divers pouvoirs territoriaux.

En général, en dépit du caractère sui generis de cette configuration de la souveraineté politique dans les fédérations, aucune conséquence analytique n'en est tirée en matière de conception de la souveraineté monétaire. La vision commune est d'envisager les systèmes et régimes monétaires contemporains sur un modèle uniforme qui ne tient aucun compte des formes organisationnelles et institutionnelles concrètes de l'ordre politique, modèle qui est conformé de fait par la norme politique de l'Etat unitaire, en parfaite syntonie avec une conception de la monnaie comme devant être réglée en fonction des seules nécessités du marché. Ainsi, comme c'est le cas en Argentine, dès que le type fédéral particulier de conformation de l'ordre politique produit dans un pays des effets institutionnels propres dans l'ordre monétaire, ces effets ne sont considérés que comme des symptômes, voire des causes de crise à simplement éliminer. En dépit de leur occurrence renouvelée sur de longues périodes et du fait qu'elles participent le plus souvent de la sortie des crises, ces institutions émergentes ne sont jamais considérées comme des innovations dont la récurrence historique indiquerait qu'elles sont peut-être des traits structurels " normaux" du type prévalent d'ordre politique et dont le développement, assumé dans le cadre d'un régime monétaire stabilisé, pourrait éventuellement aider les pays qui les inventent à sortir des impasses dans lesquelles ils sont le plus souvent enfermés.

Le cas argentin dont une spécificité, associée à la forme particulière qu'y a pris le fédéralisme, est effectivement de connaître

14 Economie et Institutions - n 10 et $11-1$ er \& 2e semestre 2007 
de façon récurrente l'émergence de monnaies fiscales provinciales, est un cas d'école sur ce plan. Ces monnaies qui y refont régulièrement surface dans les crises monétaires à répétition que connaît le pays et dont on est parfois obligé, au plus fort des crises violentes de pénurie monétaire, de reconnaître les vertus, y sont en effet généralement considérées comme des formes monétaires pathologiques dont il faut se débarrasser au plus vite pour retrouver la normalité de la monnaie unique nationale émise par le seul Etat fédéral (cf. par exemple Schvarzer et Finkelstein, 2003 ; Chelala, 2003 ; Ingham, 2004) 2.

Pourtant, comme le montre l'ethnographie économique (Dufy et Weber, 2006), l'idée d'une monnaie nationale unique apparait, confrontée aux faits, largement mythique. Elle repose pour l'essentiel sur une confusion entre compte et paiement, l'émission des moyens de paiements n'étant dans les sociétés modernes nullement le fait d'un monopole de l'Etat, mais au contraire décentralisée, plurielle et massivement le fait d'une multiplicité de banques (Servet, Théret et Yildirim, 2008). Aussi convient-il de réexaminer l'a priori normatif du caractère pathologique des monnaies provinciales argentines, voire de poser l'hypothèse de leur normalité dans le contexte fédéral argentin.

\subsection{Une tension entre unicité de l'unité de compte et pluralité des moyens de paiement}

Dans une perspective où le concept général abstrait de monnaie est pensé comme un invariant anthropologique et est donc le présupposé de toute économie monétaire, la monnaie ne peut plus être définie de façon fonctionnaliste en la rapportant à un extérieur à elle-même qui la précéderait. Elle doit l'être par des "propriétés génériques" (Ingham, 2004, 124). Une telle approche conduit à la conceptualisation suivante du fait monétaire qui nous sert ici de cadre théorique pour aborder la question de la pluralité monétaire : - La monnaie est d'abord un système de compte (définition des unités de compte, modes de leur fractionnement divisionnaire et de sommation); sous cette forme, elle est incorporée dans la psyché individuelle.

3 "Bien qu'il soit clair qu'un pays avec un système monétaire sain devrait avoir une monnaie unique convertible, le récent cas argentin montre que différentes monnaies, du fait qu'elles ont des usages distincts (dans notre pays en raison du caractère régional des émissions), peuvent cohabiter sans grandes difficultés. Nonobstant, il est important de mettre en lumière qu'il est toujours optimum qu'il y ait une seule autorité en matière d'émission. Dans le cas contraire, deux problèmes de base surgissent: l'existence d'externalités et la réduction de la certitude monétaire " (DNCFP, s.d.).

Economie et Institutions $-\mathrm{n}^{\circ} 10$ et $11-1$ er $\& 2$ e semestre 2007 
- La monnaie est également un système d'objets, ensemble articulé des objets-monnaie que sont les instruments de paiements des divers types de dettes qui doivent être honorées (pièces, billets, chèques, cartes à puce, etc.) ; elle est sous cette forme dans son état objectivé.

- La monnaie est enfin un système de régles qui établissent une correspondance entre le système de compte des dettes et créances et le système des objets-monnaie servant à leur réglement. Par ces règles, des valeurs en unités de compte sont affectées aux moyens de paiement, opération (dont on a perdu conscience à partir du moment où l'unité de compte a été inscrite sur les objets-monnaie, mais qui refait surface quand la confiance dans ces derniers est remise en question) qui peut être qualifiée de monnayage (Boyer-Xambeu, Deleplace, Gillard, 1986). La monnaie apparait ici en tant qu'institution ; elle est le produit d'un monnayage, et c'est par ce monnayage que peut s'établir une souveraineté monétaire délimitant un espace monétaire régi par un système de compte et unifié en communauté de paiement.

En effet, quand un groupe s'unifie autour d'un mode quantitatif commun de comptabilisation des valeurs, il peut former, par la médiation d'opérations cohérentes de monnayage, une communauté de paiement dans laquelle ses divers instruments de paiement sont convertibles les uns dans les autres. Dès lors divers droits et obligations sociales, quelles que soient leurs origines, peuvent prendre la forme homogène de créances et de dettes exprimées quantitativement dans un étalon commun, dans un même cadre de référence. Néanmoins, la stabilité de tout système monétaire reste en permanence menacée par une tension entre l'unicité du compte, qui définit une communauté de compte, et la pluralité des objets-monnaie, qui rappelle que cette communauté de compte est une société dans laquelle plusieurs sphères transactionnelles ou réseaux d'échanges économiques et sociaux et donc de paiement coexistent. Il y a là une contradiction structurelle qui doit être régulée ; c'est l'objet même d'un régime de monnayage que de le faire en réglant l'émission et la circulation des divers moyens de paiement, et en instituant ainsi une communauté de paiement qui se confond avec la communauté de compte.

La crise de la convertibilité argentine a parfaitement illustré cette situation en mettant en évidence la différenciation des logiques de monnayage à l'œuvre dans la société : on y a observé la circulation conjointe de monnaies monnayées en vertu d'une logique d'accumulation de capital économique (le dollar, le peso-billet, les monnaies scripturales bancaires en peso et dollar), de monnaies fiscales (la lecop nationale et les monnaies provinciales telles le patacon, le federal, la lecor, le cecacor, etc) (Sbatella, 2004; Zanabria, 2007), et enfin de monnaies sociales (creditos du réseau

16 Economie et Institutions - n 10 et $11-1$ er \& 2e semestre 2007 
global de troc et du réseau de troc solidaire, etc.) (Hintze (ed.), 2003 ; Luzzi, 2005; Ould-Ahmed, 2008, Saiag, 2008). Cette crise a également montré que, au sein des diverses sphères transactionnelles (échanges marchands, centralisation fiscale redistribution, et économie domestique socialisée - économie solidaire), il existe aussi une multiplicité de réseaux - bancaires, fiscaux (circuits provinciaux et fédéral du trésor), sociaux (réseaux d'échange locaux, trueque) - émettant leur propre monnaie et pour lesquels l'enjeu, lorsque leurs monnaies sont monnayées dans la même unité de compte, est leur échange entre elles au pair.

L'unicité de l'unité de compte apparaît ainsi en permanence contestée par la pluralité des moyens de paiement. Les interdépendances entre sphères et réseaux, dans un contexte d'unicité du compte, tendent en effet à élargir la circulation des divers moyens de paiement au-delà de leur circuit d'origine et les mettent donc en concurrence. La confiance dans la qualité de certains moyens de paiement relativement aux autres peut ainsi être mise en question et l'unicité de l'unité de compte se trouver menacée du fait que des moyens de paiement libellés dans une même unité de compte ne sont plus convertibles les uns dans les autres au pair. Il y a là péril pour la souveraineté politique qui édicte l'unité de compte et qui doit donc s'en prémunir par une régulation du système d'ensemble qui assure que les divers monnayages soient inscrits en toute légitimité dans le cadre d'institutions qui assurent la convertibilité des divers objets-monnaie entre eux à leur valeur faciale.

Dans les sociétés contemporaines, la tendance la plus évidente au fractionnement de l'espace monétaire s'exprime dans le fait que des monnaies bancaires émises en unité de compte nationale peuvent ne plus être acceptées à la parité dès lors que certaines banques émettrices paraissent en difficulté ${ }^{4}$. C'est seulement quand l'ensemble des banques bénéficie d'une garantie par une banque centrale, agissant en tant que prêteur en dernier ressort contre le risque d'illiquidité, qu'il apparaît naturel au public que les monnaies bancaires s'échangent au pair entre elles de façon routinière ainsi qu'avec la monnaie publique nationale. Et cette garantie hiérarchique, qui participe à l'établissement de la confiance dans la monnaie, a en général pour contrepartie l'acceptation par les banques d'un ensemble de règles collectives qui sont constitutives d'un système monétaire unifié.

On a moins coutume d'envisager que le même type de problème peut se poser pour la monnaie circulant dans l'ordre politique et

4 Ce fut notamment le cas aux USA au XIXème siècle où régnait une forme de free-banking. Sur ce cas, voir par exemple Le Maux, 2001 et Weiman (ed.), 2006.

Economie et Institutions $-\mathrm{n}^{\circ} 10$ et $11-1$ er $\& 2$ e semestre 2007 
alimentant son économie fiscale. Il y a plusieurs raisons à cela. La raison principale est sans doute que la majeure partie de la littérature a tendance à considérer l'Etat, fut-il en fait fédéral, comme une entité unique et personnifiée en tant que gestionnaire de la politique économique. D'autre part, dans la plupart des pays, les circuits du trésor n'ont pas d'autonomie organisationnelle et se coulent dans le moule des circuits bancaires. Ceci rend difficile d'isoler s'il y a lieu, comme dans le cas des fédérations, le problème $\mathrm{du}$ fractionnement du Trésor public en circuits différenciés territorialement de celui de la pluralité des réseaux bancaires, les banques gestionnaires des fonds du Trésor n'étant pas distinguées des banques censées privilégier le financement de l'activité économique marchande. Ainsi dans le cas du Brésil des années 1980, les Etats fédérés ont financé monétairement leurs activités mais en recourant au crédit de leurs propres banques (ultimement refinancé par la banque centrale), ce qui fait que la différenciation selon les Etats des dévaluations des monnaies scripturales émises a été largement dissimulée aux yeux du public du fait de l'écran bancaire. Cela n'a pas été le cas dans l'Argentine des années 20012003, le processus au fond identique de décentrement de l'émission de monnaie fiscale y ayant pris la forme d'émissions directes par les trésors publics provinciaux de billets de faible dénomination circulant largement dans le public. C'est ce qui rend le cas argentin exceptionnellement intéressant puisqu'il est alors possible de désintriquer la question de la fragmentation des monnaies marchandes de celle de la fragmentation des monnaies fiscales, la seconde apparaissant en toute lumière comme un phénomène différent de la première quoique fondamentalement isomorphe.

Cela dit, le fait même que bien que confrontées à un même type de pénurie monétaire, les entités fédérées brésiliennes et argentines n'ont pas eu recours à des formes de monnayage identiques n'est sans doute pas dépourvu de signification quant aux différences de relations entre souverainetés politique et monétaire dans les deux pays sur la longue durée ${ }^{5}$. Car le fractionnement de la monnaie manuelle publique qui surgit au grand jour en Argentine dans la crise et semble alors contradictoire et menaçant pour l'unité de la communauté monétaire, a en fait des fondements structurels dont témoigne l'histoire longue de ce type d'émissions. D'un certain point de vue, ce fractionnement ne fait que mettre en évidence l'autonomie relative et variable selon les provinces des divers circuits fiscaux provinciaux vis-à-vis les uns des autres et à l'égard du circuit national, autonomie normale et non pathologique compte tenu de l'organisation fédérale de l'ordre politique argentin.

5 Sur ce point, voir notamment Sgard, 2007.

18 Economie et Institutions - n 10 et $11-1$ er \& 2e semestre 2007 


\subsection{L'expérience argentine des monnaies fiscales provinciales des années 2001-2003 : mise en perspective historique}

Entre 2001 et 2003, l'Argentine est devenue le terrain d'un fédéralisme monétaire de fait. Cela n'a pas été la conséquence d'une réflexion ou d'une réforme pensée comme telle sinon une manifestation de plus de la crise du régime de currency board institué en 1991. L'ampleur de cette crise a été telle qu'elle a mis en doute non seulement la politique économique mais aussi l'organisation politique elle-même. La crise a conduit à une prolifération de stratégies de survie portées par des coalitions politiques sectorielles mouvantes et temporaires, et qui ont eu des répercussions spécifiques aux trois niveaux de gouvernement existant en Argentine : le fédéral, le provincial et le municipal. Dans un contexte de pénurie de crédit et de monnaie, chacun de ces niveaux a été confronté à une incapacité d'honorer une dette sociale croissante et le régime des transferts de ressources fiscales du fédéral au provincial - et plus secondairement du provincial au municipal - est devenu un terrain majeur de conflits politiques.

En Argentine chaque ordre de gouvernement prélève des impôts que lui sont propres et d'autres qu'il doit partager avec l'ordre de gouvernement d'échelle immédiatement moindre. Entre l'Etat fédéral et les Provinces, il y a un double système de règles de redistribution fiscale : l'un - la " coparticipación primaire " - opère la redistribution de certains impôts de la Nation à l'ensemble des Provinces; il conditionne un deuxième système par lequel ces impôts " coparticipables " (à redistribuer) sont partagés entre les Provinces ${ }^{6}$. Des systèmes similaires existent dans chaque Province où certains impôts provinciaux sont partagés entre les Municipalités.

La coparticipation fédérale est l'objet de controverses depuis l'indépendance du pays (autour du partage des droits de douane encaissés essentiellement à l'origine par Buenos Aires). Elle a en quelque sorte conditionné son organisation en tant que nation. Le système a fait l'objet de plusieurs modifications depuis sa mise en place, mais après la dernière loi de 1988, il n'a pas été formellement modifié. Depuis cette date, le rapport fiscal Etat fédéral/Provinces n'en a pas moins été renégocié en permanence à l'initiative du premier, celui-ci cherchant de manière récurrente à réduire ses obligations financières à l'égard des secondes ${ }^{7}$. Ce qui a conduit à la signature d'" accords" successifs et opportunistes entre le

6 Tous les impôts prélevés par la Nación ne sont pas coparticipables. Ainsi des impôts sur le commerce extérieur (droits de douane).

7 Bonvecchi (2006) ne recense pas moins de 15 renégociations entre 1988 (après le vote de la loi de coparticipation) et 1999.

Economie et Institutions $-\mathrm{n}^{\circ} 10$ et $11-1$ er $\& 2$ e semestre 2007 
gouvernement fédéral et les gouverneurs des Provinces.

Dans les années 1990 marquées par l'institution d'un currency board ${ }^{8}$, le déficit fiscal occasionné par la privatisation du régime de retraite et la croissance du poids de la dette extérieure a impliqué un ajustement quasi permanent des dépenses fédérales. Cet ajustement a été exporté vers les Provinces via des restrictions dans le système de péréquation et la dévolution de plusieurs services publics dont celui très couteux de l'éducation. Bref transferts de dépenses et réduction des transferts d'impôts se sont combinés pour mettre en crise les finances provinciales ou exacerber des tensions éventuellement préexistantes, les Provinces devant recourir à un endettement accru sur le marché financier pour honorer la dette sociale qui leur était transférée. La récession prolongée de la fin de la décade a porté cette crise à son paroxisme en réduisant des recettes fiscales déjà insuffisantes. Par ailleurs, les marges de manœuvre de certaines Provinces se sont également rétrécies du fait que, guidées par l'élan idéologique privatiste, elles ont procédé à la privatisation de leur banque, abandonnant ainsi toute possibilité de mobiliser un quelconque effet de circuit du Trésor pour réduire le niveau de leur dette. Dès la première menace sur le currency board survenue au milieu des années 1990, la Province de Córdoba notamment s'est retrouvée en proie à de sérieuses difficultés financières qui l'ont conduit à recourir à une pratique récurrente dans l'histoire monétaire argentine: l'émission d'une monnaie d'Etat provinciale dénommée cecor? ${ }^{\text {. }}$.

\subsubsection{Un fédéralisme monétaire en Argentine est-il légalement} possible?

L'organisation de la République Argentine en tant que fédération date de 1853, quand la Confédération se dote d'une Constitution. Cependant la Province de Buenos Aires (la plus riche) refuse à cette date d'en faire partie. A cette époque le pluralisme monétaire était la règle. La Province de Buenos Aires et celle de Corrientes avaient leur propre monnaie (de papier) alors que dans le reste du pays, on utilisait des monnaies métalliques de diverses origines. La Province de Buenos Aires a de ce fait une longue histoire d'émission de papier monnaie qui, dans le contexte métalliste de l'époque, était vue comme un obstacle à la construction de l'unité

8 Le currency board ou caisse d'émission assurait la convertibilité du peso argentin en dollar US au taux fixe et immuable de un pour un.

9 Pour une analyse du cecor dans une perspective de financement par le circuit du Trésor, cf. Capello, 1995.

20 Economie et Institutions - n ${ }^{\circ} 10$ et $11-1$ er \& 2e semestre 2007 
nationale $^{10}$ (Irigoin, 2000). Ce n'est toutefois qu'en 1994 que la Constitution fédérale sera réformée et ne donnera plus au Congrès national le droit d'autoriser les Provinces à émettre leur propre monnaie. Cependant on peut toujours lire à son article 126 que "Les Provinces n'exercent pas le pouvoir délégué à la Nation. Elles ne peuvent (...) créer des banques ayant la faculté d'émettre des billets, sans l'autorisation du Congrès Fédéral (ne pas souligner)". Cet article laisse donc ouverte une possibilité légale pour les Provinces d'émettre du papier monnaie via leur banque.

Cela dit, lorsqu'en 2001 et 2002 la majorité des gouvernements provinciaux vont émettre des billets provinciaux, non seulement ceux-ci ne passent pas nécessairement par leurs banques pour ce faire, mais surtout ils le font sans cet accord préalable. Les Provinces n'en défendirent pas moins la légalité d'une telle mesure, entérinée par les Cours Suprêmes provinciales, sur la base d'un argument de force majeure et de "nécessité et urgence" face à une crise économique et sociale remettant en cause leur continuité en tant qu'Etats. Selon cet argument, toute Province "face à l'inexistence de monnaie constitutionnelle pour solder ses dettes n'a pas d'autre alternative que d'émettre sa propre monnaie sans la permission de l'Assemblée argentine, notamment pour empêcher le chaos économique et social " (Sagüés, 2001). Cette posture trouve en fait sa justification dans le pacte de San Nicolás signé en 1852 et qui appelait à la mise sur pied d'un Congrès Général Fédératif Constituant devant "s'occuper (...) de l'administration générale du Pays (...), de la manière la plus compatible possible avec (...) la souveraineté, la liberté et l'indépendance de chacune des Provinces." Et elle a été de fait acceptée par un gouvernement fédéral incapable d'honorer ses engagements vis-à-vis de celles-ci et qui va lui-même émettre une monnaie fiscale spécifique pour régler ses dettes à leur égard, la lecop.

\subsubsection{Des émissions récurrentes de papier monnaie}

C'est en tant que souvenir des moments fondateurs de la fédération qu'a perduré dans le texte de la première Constitution nationale la faculté donnée au Congrès d'autoriser l'émission provinciale de billets. Cette faculté n'est pas tombée immédiatement

10 "Utile ou nocif, bon ou mauvais, le papier-monnaie est un fait à Buenos Aires, et un fait qui compte depuis un demi-siècle ; c'est à vrai dire une coutume, une institution, un intérêt public de premier ordre dans cette province. ... Mais il n'y a qu'un moyen de normaliser le papier-monnaie de Buenos Aires: nationaliser son crédit public, son trésor public local, ou mieux dit d'un seul trait : nationaliser Buenos Aires" (Alberdi, 1895 (1996), p. 268). Alberdi est considéré comme le père de la Constitution argentine.

Economie et Institutions $-\mathrm{n}^{\circ} 10$ et $11-1$ er $\& 2$ e semestre 2007 
en désuétude et elle a été utilisée en 1876, 1881, 1883 et 1885. Par ailleurs, le besoin d'un accord préalable du Congrès n'a pas empêché certains gouvernements provinciaux de renouer avec cette pratique dans l'entre-deux guerres sans cet accord, comme en témoignent divers arrêts de la Cour Suprême de Justice qui leur interdisent d'émettre des monnaies - cas "Galleti" (20-12-1926) et "Viñuelas" (12-09-1927) (Capón Filas, 2003). Après la création de la Banque centrale en 1935, le phénomène semble disparaître, ce qui coïncide avec une longue période de croissance industrielle tirée par la substitution des importations et gérée par des régimes autoritaires.

Il faut attendre 1983 pour voir le phénomène réémerger. Cette année là, la Province de Salta émet des billets (bonos) et est suivie en 1985 dans cette voie par les Provinces voisines de Jujuy, Tucuman et la Rioja, émissions qui auront pour effet de redynamiser l'activité économique des provinces concernées (Schuldt, 1997). Plus significativement, la circulation de ces monnaies perdure durant une grande partie des années 1990, et même, pour une partie d'entre elles, jusqu'en 2003, comme dans le cas des bonos de Tucumán (bocade) et de Catamarca (bono publico émis en 1993). En 1995 et 1996, on l'a déjà évoqué, le gouvernement de la province de Cordoba, troisième PIB du pays derrière la province et la Ville de Buenos Aires, émet diverses séries de cecor. Le succès de ces émissions fera la réputation de son gouverneur, membre du Parti Radical, Ramon Mestre ${ }^{11}$. Cette réputation fait qu'en 1999, celui-ci est nommé interventor par le gouvernement fédéral pour remettre sur pied l'administration publique de la province de Corrientes en proie à une crise institutionnelle, financière et sociale profonde ${ }^{12}$. Le déséquilibre des comptes de cette Province est alors financé par l'émission d'un nouveau bono calqué du cecor, le cecacor, lequel va rester en circulation - avec une beaucoup moins bonne fortune que celui-ci - jusqu'à la fin de 2003.

1.3.3. Les causes de leur renouveau dans les années 1990 et 20012002

L'économie argentine se caractérise par son instabilité, ce qui ne cesse d'avoir des répercussions sur le régime de coparticipación des impôts fédéraux. La volatilité de l'économie pose de sérieux défis aux finances provinciales et pour rendre plus flexible la distribution des transferts régie par la loi de 1988 sur la coparticipation, divers

11 En 1996, la Province de Missiones émet également un bono intitulé cemis.

12 Cf. "Mestre lanza bono ahora en Corrientes ", 1999, www.ambitoweb.com/edicionesanteriores/afinancieroback/99-1221/economia002.htm 
mécanismes additionnels de négociations et d'assistance financière aux Provinces par la Nacion ont été mis en place et pris de l'ampleur (graphique 1).

\section{Graphique 1 : Coparticipation en \% de 1'ensemble des transferts fédéraux-provinciaux}

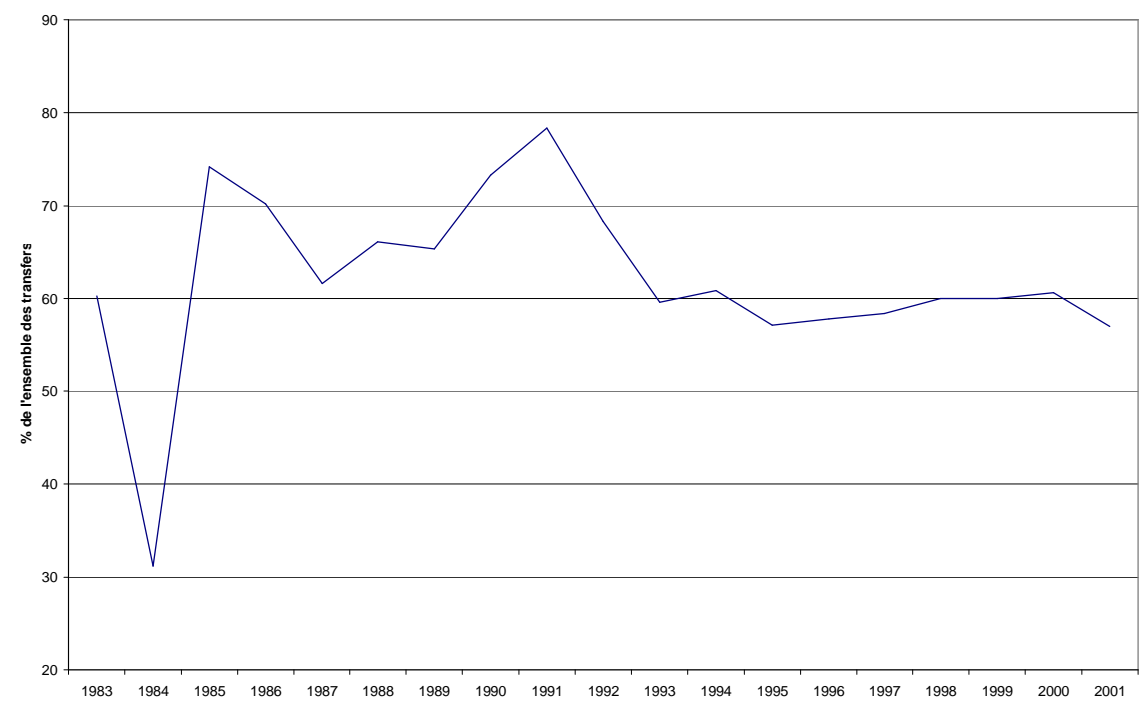

Source : Elaboration propre à partir de données du Ministère de l'Economie

On a déjà signalé que, durant la seconde moitié des années 90, les Provinces ont perdu l'essentiel de leurs marges de manœuvre dans la gestion de leur budget. D'un côté, en effet, l'impossibilité pour les Provinces, inscrite dans le régime de currency board, de réescompter les papiers de leurs banques publiques, rendait caduque cette voie de financement pour celles qui résistaient à l'idée de privatiser leur banque provinciale. De l'autre, les Provinces étaient conduites à aliéner leurs ressources au titre de la coparticipation dans la mesure où elles devaient emprunter auprès du système financier en garantissant leurs emprunts à partir de ces ressources (Cetrangelo et Gatto, 2002). De cette manière, les gouvernements provinciaux se sont retrouvés exposés d'une part à l'arbitraire de la distribution des fonds d'origine fédérale, d'autre part à l'évolution de la conjoncture macroéconomique, elle-même fonction de la politique économique fédérale, dont les effets jouaient fortement sur leurs recettes fiscales. 
Par ailleurs, cet amenuisement des sources de financement s'est accompagné d'une augmentation des charges de la "dette sociale" incombant aux gouvernements provinciaux. En effet, "la fourniture de l'éducation de base et de soins de santé a été transférée aux Provinces au cours d'un long processus qui s'est achevé avec les transferts de 1978 et 1993. Dans les deux cas, le processus de décentralisation des compétences a été mené sans un transfert équivalent de ressources financières " (ibid.). La proportion élevée de dépenses en personnel destinées à couvrir les besoins d'éducation et de santé qui en est résultée a rendu la dépense publique provinciale difficile à réduire (graphique 2).

\section{Graphique 2 : Structure des dépenses par finalité et niveau de gouvernement}

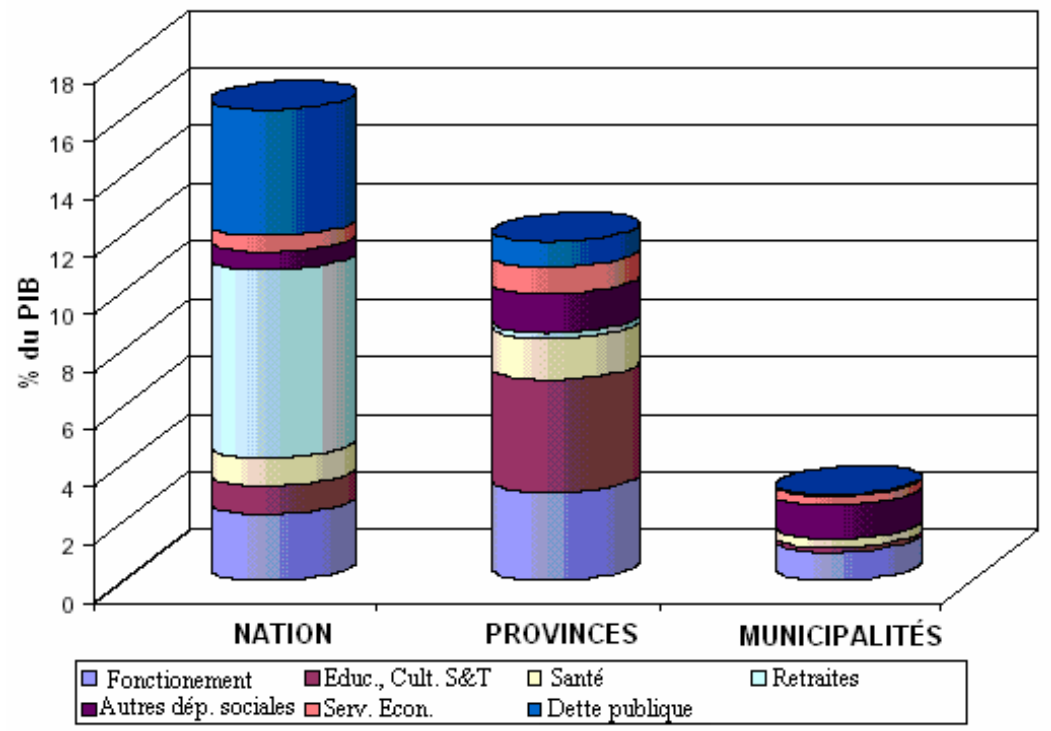

Source: Cetrángolo, Oscar et Gatto, Francisco. Op. Cit

Cette rigidité de la dépense à la baisse, combinée aux restrictions institutionnelles associées à la disparition du prêteur en dernier ressort impliquée par le currency board, a provoqué ou accentué fortement la fragilité financière des Provinces. D'où l'apparition du cecor à Cordoba, quand le currency board est soumis à une première épreuve en 1995 avec la crise financière mexicaine et l'effet "tequila", et que le nouveau gouverneur doit faire face à un durcissement des conditions d'accès au crédit qui l'empêche d'honorer les dettes contractées par le gouvernement antérieur.

Dans le cas de Corrientes, les difficultés financières étaient plus structurelles. Ainsi, quand 1'Etat fédéral intervient pour prendre en charge l'administration de la Province, environ 50\% des fonds au

24 Economie et Institutions - n 10 et $11-1$ er \& 2e semestre 2007 
titre de la coparticipation que celle-ci aurait du recevoir étaient retenus comme garantie d'emprunts antérieurs. Mais l'émission du cecacor en 1999 se produit aussi au moment où la situation macroéconomique de l'Argentine dans son ensemble se détériore fortement et quand s'installe la longue récession qui va finir par emporter le régime de "répression monétaire " en place.

A partir de 1998, l'économie argentine connaît en effet une chute constante de son PIB. Cette dégradation entraîne des besoins accrus de financement de la Nacion (l'Etat fédéral), mais aussi des Provinces. Le poids du service de la dette extérieure et le gouffre qu'était devenu le système de retraites après sa privatisation pèsent alors très lourds sur le budget national ${ }^{13}$. De plus, les mauvaises performances du secteur extérieur exigent une entrée permanente de capitaux pour que puisse être maintenue la parité peso/dollar, sauf à ce que la circulation régresse, la masse monétaire se contractant (voir graphique 3).

Graphique 3 : Degré de liquidité (M3 privée/PIB)

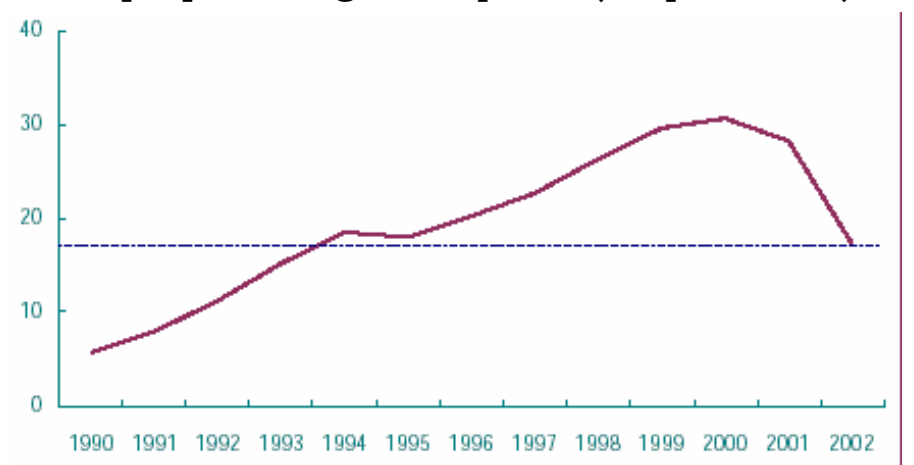

Source : BCRA, Informe Monetario Mensual, diciembre 2002.

Le mécanisme d'ajustement prévu implique une chute des prix et des salaires, mais celle-ci n'a pas l'ampleur requise. Des problèmes de pénurie monétaire se manifestent donc et renforcent la récession (cf. graphique 4).

13 Pour une analyse détaillée, voir Damill, Frenkel et Juvenal, 2004.

Economie et Institutions $-\mathrm{n}^{\circ} 10$ et $11-1$ er $\& 2$ e semestre 2007 
Graphique 4 : Variations trimestrielles du PIB argentin

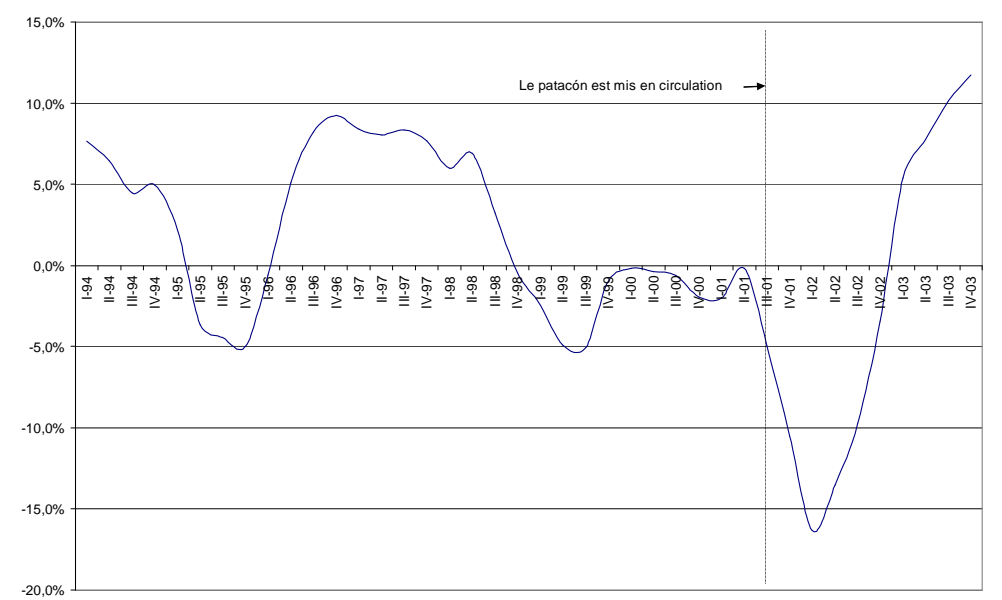

Source : Elaboration propre à partir de données du Ministère de l'Economie

Mais loin d'envisager de sortir au plus vite du currency board, les autorités nationales cherchent au contraire à l'approfondir de manière à maintenir sa crédibilité et ainsi permettre l'entrée de capitaux étrangers qui manquent tant pour rééquilibrer le système. Aussi mettent-elles en œuvre des mesures draconiennes qui commencent en 1999 par un compromis entre la Nación et les Provinces par lequel la première s'engage à assurer aux secondes, au titre de la coparticipation, une somme fixe plus faible que celle préalablement convenue mais non liée aux recettes fiscales effectives. Par ce pacte, les Provinces s'assurent un minimum de ressources dans un contexte de forte incertitude, même si, à première vue, elles sont perdantes ${ }^{14}$. La Nacion parie quant à elle sur l'amélioration de sa performance fiscale. Le problème est alors que l'Etat fédéral à nouveau ne va pas tenir parole. En effet, fin juillet 2001, le vote de la

14 "En décembre 1999, une des premières mesures du nouveau gouvernement fut d'arriver à un accord avec les provinces sur un nouveau compromis fédéral. Un élément important de cet accord fut que durant l'année 2000, les Provinces recevraient un montant fixe de transferts automatiques. Cela apportait de la prévisibilité de leurs revenus aux Provinces, mais en contrepartie, le montant à verser était programmé pour permettre au gouvernement fédéral de conserver une plus grande proportion du surcroît de ressources attendues tant du fait d'une reprise économique que d'une pression fiscale fédérale plus élevée. En 2001, les Provinces commencèrent à recevoir l'équivalent de la moyenne des montants légaux des années antérieures, ou pour le moins une garantie minima fixée à un niveau $1 \%$ plus élevé que les montants fixés pour l'année 2000. En résumé, cet accord représentait une perte anticipée considérable pour les Provinces en termes de transferts totaux. "(Banco Mundial, 2001, p. 22).

26 Economie et Institutions $-\mathrm{n}^{\circ} 10$ et $11-1$ er $\& 2$ e semestre 2007 
"loi du déficit zéro", destiné à remplir les conditions d'un refinancement par le FMI, implique un brutal ajustement des salaires, des retraites et des transferts fiscaux vers les Provinces, ce qui signifie que le gouvernement fédéral ne reconnaît plus le compromis de 1999: début octobre 2001, sa dette à l'égard des Provinces est de 488,1 millions de pesos ${ }^{15}$. Les Provinces, y compris celles gouvernées par des membres du Parti au pouvoir au niveau fédéral, menacent alors de poursuivre l'Etat fédéral en justice pour obtenir les fonds promis.

\subsubsection{La construction de la confiance en pratique}

A la mi 2001 il est devenu clair que c'est la faillite complète d'une majorité d'Etats provinciaux qui est en jeu. Car non seulement l'Etat fédéral ne respecte pas ses engagements en matière de transferts, mais les Provinces subissent une réduction de leurs ressources propres due à ce que pour la plupart d'entre elles leur impôt principal, l'impôt sur le chiffre d'affaires, voit son rendement décliner avec la récession, au même titre d'ailleurs que leurs recettes d'impôts sur les produits (dans l'immobilier et l'automobile principalement). S'ouvre alors une nouvelle vague d'émissions de monnaies provinciales. Le phénomène reprend d'abord cette fois dans la Province de Buenos Aires avec l'émission du patacón. Celle-ci est suivie jusqu'à mi 2002 par d'autres émissions, de telle sorte que plus de la moitié des Provinces (14 sur 24) disposent à cette date de leur propre monnaie. Ces monnaies en arrivent à représenter près de $40 \%$ de la circulation monétaire, fournissant manifestement l'apport de liquidité manquant. Ce processus d'émergence de monnaies complémentaires plus que concurrentes, contrairement à ce qu'affirme la vision standard ${ }^{16}$, a été quasi spontané. Le fait qu'il ait été ensuite plus ou moins soutenu par le gouvernement fédéral a été fonction du degré de nécessité pour celui-ci de s'appuyer sur des provinces ayant un grand nombre de représentants au Parlement fédéral.

15 Standard \& Poor's, Octobre 2001

16 Cf. par exemple Argañaraz, Capello et Garzon, 2003 et Colliac, 2004.

Economie et Institutions $-\mathrm{n}^{\circ} 10$ et $11-1$ er $\& 2$ e semestre 2007 
Graphique 5 : Pesos et monnaies provinciales en \% du total

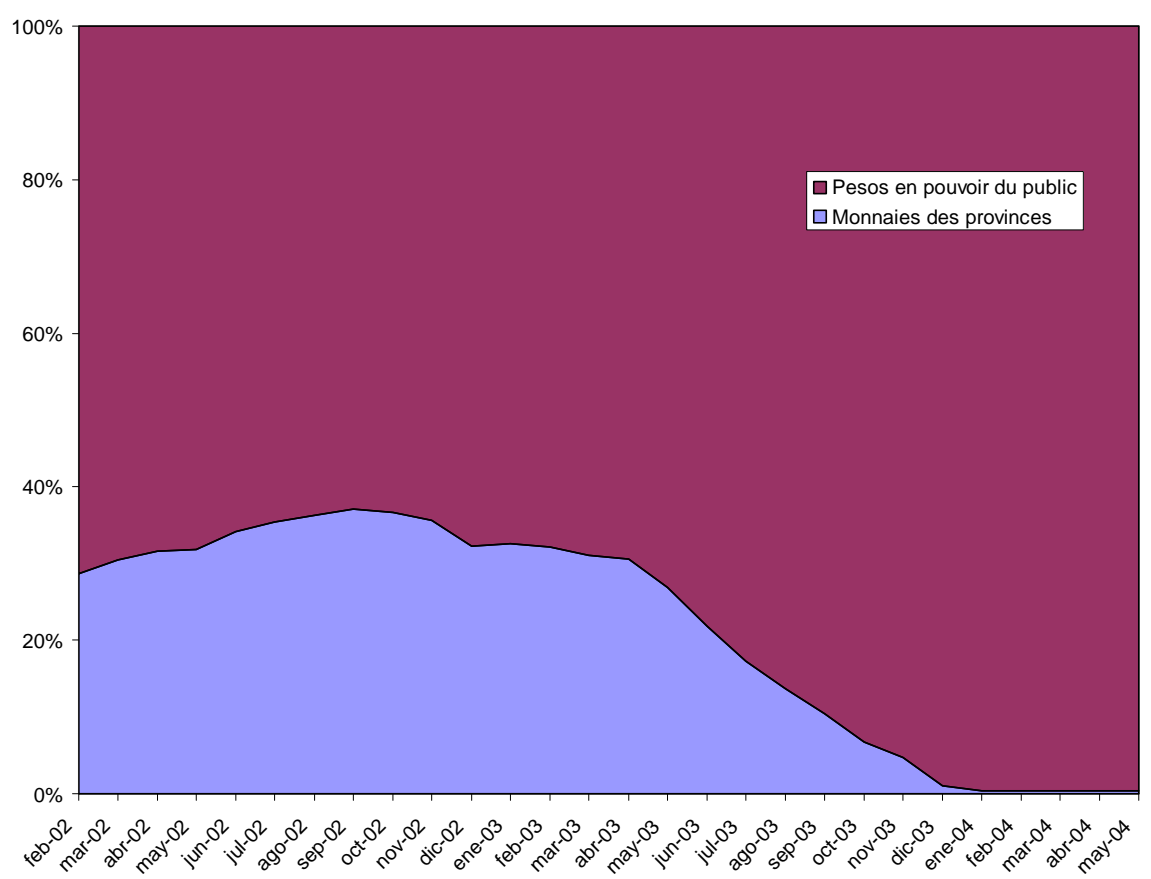

Source : Elaboration propre avec des données du Ministère de l'Economie

Ces monnaies ont eu des sorts divers, certaines connaissant un succès véritable (comme dans le cas du patacón, mais aussi de la lecor émise par la Province de Cordoba) et d'autres des échecs (comme avec le federal émis en Entre-Rios, mais aussi et surtout avec le cecacor dans la province de Corrientes). Leurs destins variables selon les provinces sont liés d'une part aux possibilités objectives de leur absorption par les économies régionales, d'autre part aux stratégies choisies pour les fonder en confiance auprès de leurs utilisateurs. Il a été montré ailleurs qu'on ne pouvait assimiler la confiance à la notion de crédibilité et qu'il fallait en distinguer au moins trois formes : la confiance méthodique, la confiance hiérarchique et la confiance éthique ${ }^{17}$. Pour être lien de confiance, la monnaie requiert le jeu combiné de ces trois formes. La confiance méthodique est celle la plus couramment mise en avant : elle relève du comportement individuel selon lequel chacun accepte la monnaie sans se poser de questions parce que les autres font de même, ce qui signifie qu'on croît de façon routinière qu'elle sera acceptée demain et

17 Cf. les introductions de Aglietta et Orléan (dir.), 1998 et Théret (dir.), 2007.

28 Economie et Institutions $-\mathrm{n}^{\circ} 10$ et $11-1$ er $\& 2$ e semestre 2007 
après-demain à sa valeur du jour. La forme hiérarchique de la confiance renvoie, quant à elle, au fait que la stabilité de l'unité de compte et de la valeur en unités de compte des divers moyens de paiement est garantie par un pouvoir collectif qui lui-même inspire confiance en tant que représentant ou partie prenante d'une souveraineté protectrice. La confiance éthique enfin renvoie à l'autorité symbolique du système des valeurs et normes collectives qui fonde l'appartenance sociale; une monnaie dispose d'une confiance éthique dès lors que ses modes d'émission, de distribution et de circulation paraissent assurer la reproduction de la société en tant que communauté d'appartenance, c'est-à-dire dans le respect de ses valeurs et normes constitutives. La confiance éthique est à la confiance hiérarchique ce que la légitimité est à la légalité et ce que l'autorité symbolique est au pouvoir politique.

Ce cadre d'analyse en trois formes de la confiance nous sert dans la suite de cet article à examiner les destinées différenciées de diverses monnaies provinciales argentines. Il fait en effet jouer un rôle central à la souveraineté dans l'établissement de la confiance en posant que si le pouvoir qui exerce la souveraineté sur la monnaie est légitime, la confiance dans la monnaie est assurée, la confiance méthodique étant garantie par la confiance hiérarchique et celle-ci par la confiance éthique. Il permet aussi de saisir que dans les ordres politiques fédératifs où la question de la souveraineté se complexifie dans la mesure où son exercice est partagé entre les ordres fédéral et fédéré de gouvernement, non seulement les normes et valeurs d'appartenance politique et sociale fondant la confiance éthique sont différentes de celles valant dans les Etats unitaires, mais aussi le problème de la construction de la confiance hiérarchique est dédoublé. Il ne s'agit plus seulement en effet d'établir une régulation du monnayage bancaire des monnaies marchandes à l'échelle de la fédération, mais aussi de maintenir la légitimité du contrôle fédéral sur l'émission des monnaies fiscales, contrôle qui constitue en général un enjeu central des pactes fédératifs et des systèmes de relations fisco-financières entre les ordres fédéral et fédéré de gouvernement. Un tel contrôle est soumis aux tensions qui travaillent de tels pactes, surtout lorsque l'Etat fédéral est soumis à des contraintes financières extérieures fortes. 


\section{Les monnaies fiscales des provinces de Buenos Aires et Entre Rios}

Commençons par l'examen des cas contrastés du patacon et du federal émis respectivement dans les provinces de Buenos Aires et Entre Rios.

\subsection{Le succès du patacon, province de Buenos Aires}

Début juillet 2001, le gouvernement de la province de Buenos Aires, de loin la plus grande des provinces argentines, réclame à l'Etat fédéral un arriéré de paiement d'environ 580 millions de pesos. Le 5 juillet, le gouverneur, le péroniste Ruckauf, annonce publiquement que dans ces conditions imposées par l'Etat fédéral, il est obligé d'outrepasser les principes du currency board et que le $13^{\text {ème }}$ mois ${ }^{18}$ versé aux fonctionnaires va être payé avec des bonos qui " en réalité sont bien une monnaie ", comme le gouverneur lui-même le déclare le lendemain ${ }^{19}$. Alors que dans un contexte de diminution de la masse monétaire en circulation, le gouvernement fédéral procédait à une restriction des salaires nominaux, le gouvernement provincial ouvrait de la sorte à ses salariés une autre possibilité, à savoir défendre par l'action collective la valeur de leurs revenus en mettant en circulation une monnaie complémentaire. Ainsi le Ministre Sarghini pouvait-il affirmer le jour même de la mise en circulation du patacón :

"Défendre le patacón, c'est défendre le pouvoir d'achat des 180.000 bonaerenses ${ }^{20}$ qui le recevront comme partie de leurs salaires et aussi de ceux qui l'accepteront dans leurs transactions (...). Dès lors qu'il commencera à circuler, nous, le gouvernement, les employés publics et les entrepreneurs devrons développer une véritable croisade pour la défense du patacón, car la seule autre alternative aurait été de prendre des mesures qui auraient encore accru la contraction de la demande et corrélativement son impact social négatif ". ${ }^{21}$

L'initiative se veut aussi une réponse à une situation où le corset qu'imposait le compromis sur le "déficit zéro " et son corrélat, le manque de circulant, mettent en péril la continuité du fonctionnement de l'Etat provincial et menacent donc les conditions

18 En Argentine le treizième mois est payé par moitié en juillet et en décembre.

19 Journal El Dia, édition du 6 septembre 2001, La Plata.

20 Les habitants de la Province de Buenos Aires.

21 Journal Hoy, mardi 21 août 2001, p. 9. La Plata.

30 Economie et Institutions - n 10 et $11-1$ er \& 2e semestre 2007 
de vie non seulement des employés de la Province, mais aussi de l'ensemble des "bonaerenses " utilisateurs des services publics. En effet, plus de $90 \%$ des fonctionnaires provinciaux travaillent dans l'éducation, la santé ou la sécurité. L'émission de patacacones, en permettant d'éviter de fortes baisses de salaires pour les fonctionnaires de ces services, fait que l'éducation, le système de santé et la police peuvent continuer à fonctionner, même si c'est en situation de précarité. Le patacon est ainsi fondé en légitimité, à défaut de l'être parfaitement en légalité; il s'inscrit en tant qu'élément clef de la permanence des missions de l'Etat provincial. C'est sur cette base que la Cour Suprême de Justice de la province a statué en sa faveur lors d'un recours en justice des syndicats de fonctionnaires soucieux d'empêcher que ceux-ci soient payés avec une mauvaise monnaie et voient de ce fait s'effondrer leurs salaires. S'agissant d'une situation de " nécessité et urgence ", l'émission de patacones est décrétée légitime et donc légale à l'échelle de la province en tant que destinée à assurer la permanence de l'Etat provincial et de sa capacité à exercer ses compétences. Cette dimension éthique du patacon a été également renforcée par le fait que ce sont seulement les employés qui ont les salaires les plus élevés (au-delà de 740 pesos) qui sont payés partiellement en patacones. Ainsi, par delà la symbolique de la nécessaire permanence de l'Etat provincial et de sa capacité à remplir ses missions sociales et de service public, un principe éthique de justice distributive est également mobilisé.

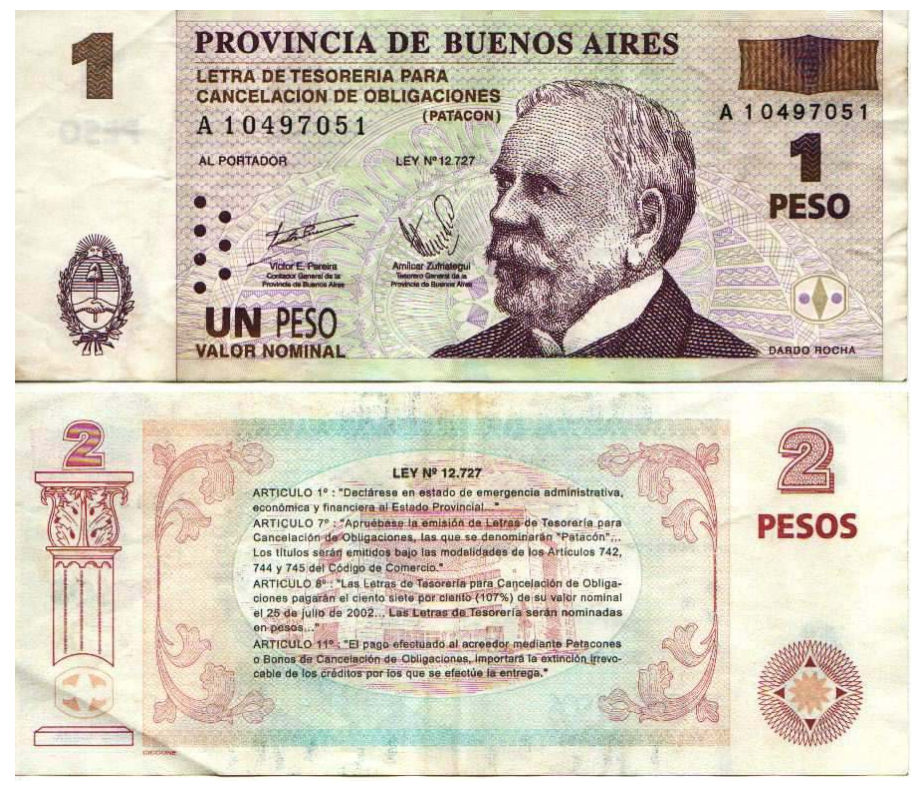


Ce fondement éthico-symbolique fort du patacon permet de comprendre que le Parlement provincial, bien que dominé par l'opposition (la Alianza), ne se soit pas opposé à l'émission de la nouvelle monnaie, comme ce fut le cas dans l'Entre-Rios où une configuration politique inverse est observable. En revanche, le Parlement a poussé le gouvernement péroniste à prendre les mesures nécessaires pour assurer l'acceptation du patacon par les entreprises du secteur des services. La raison en était simple : la Province avait passé un accord avec les municipalités en vertu duquel elle assurait avec le patacon un montant de coparticipation (provinciale) supérieur aux montants découlant d'une application stricte des normes de redistribution en vigueur. Le patacón fut ainsi rapidement accepté et soutenu par les municipalités. Le fait que le localisme des sénateurs et députés provinciaux soit plus affirmée que dans le Parlement national, permet de comprendre que les nécessités locales de la continuité de l'Etat provincial aient pu ainsi prévaloir sur la confrontation politique.

Si on se tourne maintenant du côté du marché, on constate que très vite la nouvelle monnaie a été adoptée dans le secteur concurrentiel. Les commerçants avaient en effet conscience que les acheteurs porteurs de patacones se fourniraient là où ceux-ci seraient acceptés comme s'il s'agissait de pesos, c'est-à-dire à leur valeur faciale. Ainsi les vitrines des boutiques se sont garnies d'autocollants du type: "Je suis argentin, j'accepte les patacones". Quant à ceux qui opéraient en situation de monopole, ils ont dû faire face à des protestations répétées des usagers qui ne voulaient acquitter leurs dettes qu'avec des patacones ainsi qu'à de fortes pressions du gouvernement provincial et des municipalités. En définitive, l'acceptation du patacon a été quasiment immédiate, surtout dans la ville de La Plata, capitale de la province. Un sondage sur les ventes de détail dans cette ville indique que toutes les boutiques enquêtées les ont acceptés pendant toute leur existence ${ }^{22}$. Notons également qu'à partir de février 2002, aucun commerce ne demandait que le possesseur du patacón soit employé public, comme c'était le cas au tout début. On peut ainsi dire que la confiance méthodique dans le patacon a été directement assurée par une confiance éthique. Mais d'autres éléments, notamment une politique active envers les acteurs de marché, ont aussi joué fortement dans la stabilisation et le maintien de cette confiance.

22 "Certains commerces offrirent de prendre les patacones à un prix supérieur à leur valeur faciale $(1,05)$, ce que la Province a essayé d'empêcher " (Fahler Lopez, 2001, p. 5).

32 Economie et Institutions - n 10 et $11-1$ er \& 2e semestre 2007 
Assurer une pleine circulation du patacón au pair fut en effet une politique centrale du gouvernement provincial. Pour ce faire, celui-ci mit en œuvre une stratégie spécifique, elle-même inspirée de l'expérience du cecor à Córdoba ${ }^{23}$. C'est ainsi qu'une série de négociations a été menée avec le secteur marchand entre l'annonce de l'émission du patacon et sa mise en circulation. Une attention toute particulière a été portée à une entente avec les entreprises privatisées de services publics pour qu'elles acceptent un pourcentage minimum de patacones en paiement de leurs services. Les premières négociations ont été dirigées vers les coopératives des services électriques qui assurent l'approvisionnement à l'intérieur de la province, puis le gouvernement s'est s'attaqué aux fournisseurs des plus grands centres urbains, s'agissant, après avoir obtenu un accord avec les petites et moyennes entreprises, de négocier en position de force avec les grandes sociétés. Là encore, le gouvernement provincial a misé sur le local pour faire pression sur les supermarchés, ce qui allait de soi compte tenu de la concentration des employés publics à La Plata : environ $40 \%$ des premiers patacones émis pour un montant de 90 millions de pesos étaient destinés aux habitants de la capitale. Dans cette ville en particulier, le patacon est devenu une monnaie quasi-sociale ou communautaire, un bien public que la population dans sa grande majorité s'est appropriée et a ainsi été capable d'imposer aux forces du marché. Les conditions symboliques de l'institution du patacon comme monnaie équivalente au peso ont ainsi été constituées par une action collective mobilisant la population et ses représentants à tous les niveaux de l'ordre politique provincial.

On a dit précédemment que la confiance hiérarchique dans une monnaie était intimement liee à l'existence d'une garantie institutionnelle, par un pouvoir collectif supérieur, de la valeur en unité de compte des moyens de paiements constitutifs de cette monnaie. Dans le cas du patacon, on doit alors se demander quelle était la garantie que le pouvoir hiérarchique du gouvernement provincial pouvait bien mobiliser pour stabiliser sa valeur par rapport au peso. Plusieurs éléments sont ici à prendre en considération.

Tout d'abord, c'est fondamental, le patacon était accepté en paiement des impôts provinciaux et il circulait donc dans le cadre d'un circuit du trésor provincial. Bien qu'il fut porteur d'un intérêt de $7 \%$ annuel comme un bon du trésor ${ }^{24}$, son caractère libératoire des

23 Entretien avec M. Dante Sica, responsable du cabinet du Ministre de la production, La Plata, novembre 2004.

24 Même si cette "rentabilité " du patacon est apparue secondaire par rapport à sa fonction monétaire, on doit remarquer que les deux monnaies provinciales ici examinées qu'on peut créditer d'avoir inspiré confiance

Economie et Institutions $-\mathrm{n}^{\circ} 10$ et $11-1$ er $\& 2$ e semestre 2007 
dettes fiscales provinciales lui donnait aussi un caractère monétaire en accord avec sa physionomie de billets de faible dénomination. Or le circuit de la Province de Buenos Aires est large car il s'agit d'une grosse province - 36,8\% du total de la population argentine, 33,4\% du PNG, $48 \%$ des exportations, la plus forte population urbaine - et densité - du pays hors la Ville de Buenos Aires, sorte de district fédéral -, par ailleurs dotée de ressources propres importantes - 48\% $\mathrm{du}$ total de ses ressources budgétaires et $35 \%$ des dépenses. Ce circuit provincial du Trésor était aussi bien structuré dans la mesure où la Banque Provinciale n'avait pas été privatisée et disposait d'un grand réseau de succursales ${ }^{25}$.

De plus, peu de temps après la mise en circulation des patacones, l'Etat fédéral les a aussi accepté en paiement des impôts nationaux à la suite d'un accord passé le 31 août 2001 entre le ministre fédéral des finances, Domingo Cavallo (le père du currency board), et le gouverneur Ruckauf (pourtant membre de l'opposition officielle). En vertu de cet accord qui privilégie la Province de Buenos Aires par rapport aux autres Provinces émettrices, les patacones reçus par la Nation au titre des impôts fédéraux doivent retourner à la Province de Buenos Aires comme partie des paiements de transferts fédéraux au titre de la coparticipation. Cela a pour effet d'élargir considérablement la taille du circuit du Trésor sur lequel peut s'appuyer le gouvernement provincial pour s'autofinancer. Par ailleurs, cela met le patacon à quasi égalité avec la lecop, la monnaie pan-provinciale émise fin 2001 par la Nation pour financer les transferts aux Provinces (et admise en paiement de tous les impôts), et lui permet de circuler largement en dehors des frontières de sa province d'origine ${ }^{26}$. Pour beaucoup d'observateurs, un tel accord est la preuve du caractère politique d'une relation privilégiée entre la coalition gouvernementale nationale en manque de légitimité et le chef de file de l'opposition péroniste.

rapportaient un intérêt de $7 \%$ alors que celles qui se sont fort éloignées de la parité (federal et cecacor) ne portaient un taux d'intérêt que de $4 \%$ (cf. infra). 25 "Le Bapro, la banque de la Province, représente $12 \%$ de l'ensemble du système bancaire national, mais aussi sans doute plus de $30 \%$ du système bancaire provincial. Avec des centaines de succursales et de caisses automatiques, elle a joué un rôle central dans l'instrumentation du patacon. Une banque privée, sujette aux directives de la Banque Centrale et moins compromise politiquement avec la Province, n'aurait sans doute pas été aussi fonctionnelle à la diffusion du patacon. Plus des $2 / 3$ des patacones en circulation n'étaient pas physiquement dans les mains des particuliers, mais déposés au Bapro " (Eggers, 2001).

26 La lecop devait d'ailleurs à l'origine absorber le patacon, selon Fahler Lopez, 2001.

34 Economie et Institutions - n 10 et $11-1$ er \& 2e semestre 2007 

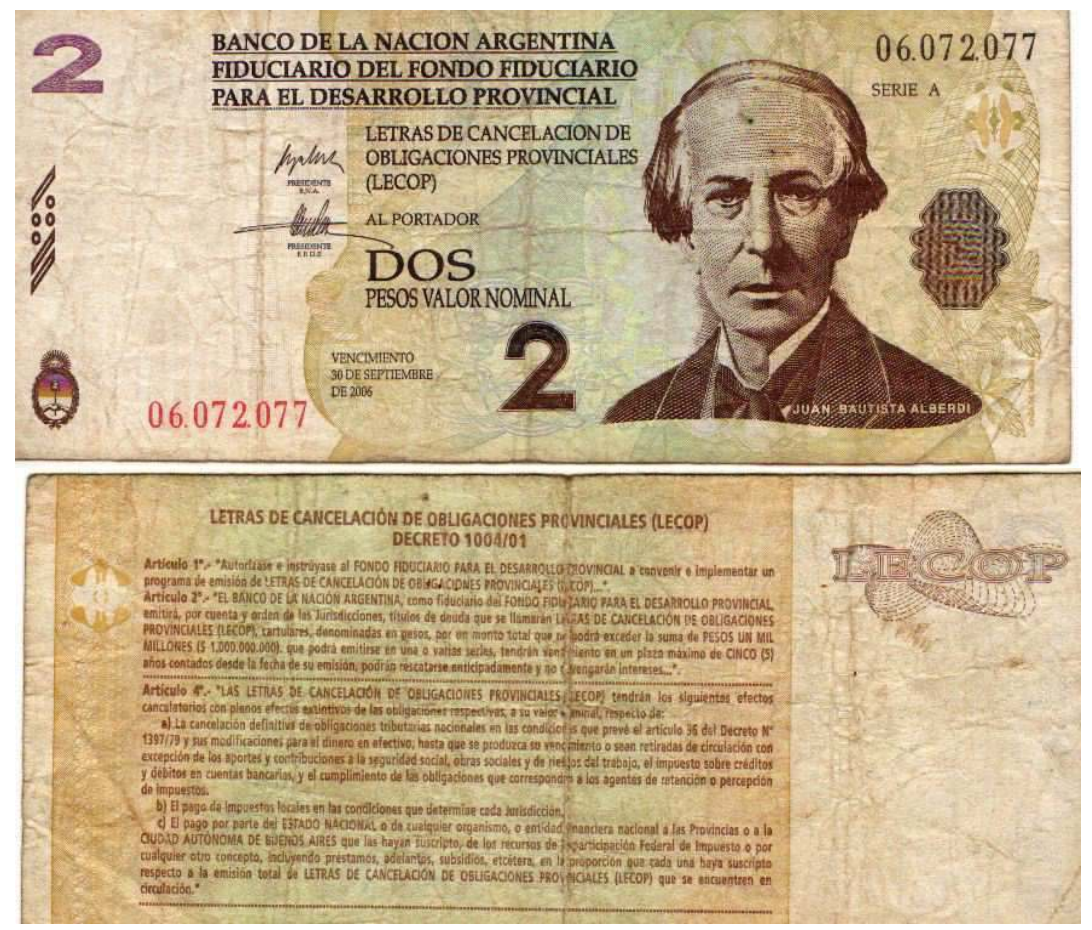

Enfin, les montant maximaux d'émission des patacones fixés par la loi ont été respectés et sont restés sous contrôle. Dans le cadre de l'accord politique entre gouvernement et opposition déjà noté, le pouvoir exécutif demandait de nouvelles autorisations au Parlement provincial en cas de besoin. La circulation a atteint $53,4 \%$ des revenus fiscaux propres à la Province et $3,2 \%$ de son Produit Brut Géographique en 2002 (soit encore 33\% du total de la circulation provinciale au point culminant de mars 2003). En fait, les autorités politiques se sont gardées d'émettre au-delà de ce dont elles avaient besoin pour financer les dépenses les plus importantes : salaires et fournisseurs de produits les plus nécessaires.

Cette "mesure " monétaire a été renforcée du fait qu'il n'y a pas eu d'émission secondaire via le crédit. Bien que les patacones puissent être mis en dépôt sur des comptes courants, sans intérêt, à la banque de la Province (la plupart y restaient et circulaient par voie scripturale), il n'y avait pas de prêts possibles en cette monnaie. Quand les recettes des impôts ont commencé à augmenter, le gouvernement a remplacé progressivement les patacones par des pesos pour payer les salaires. Après la signature en juin 2003 de l'accord avec la Nation pour éliminer le patacon dans le cadre du programme d'unification monétaire, la Province s'est engagée rapidement dans l'opération. En juillet, la moitié du 13ème mois a été payée en pesos, de même que l'intégralité des salaires du mois 
d'août. Ainsi la Province de Buenos Aires a été l'une des Provinces parmi les plus conservatrices dans l'utilisation de cet instrument de paiement.

Tableau 1 : Circulation des patacones (millions de pesos)

\begin{tabular}{|l|l|l|l|}
\hline & Fin 2001 & Fin 2002 & Fin 2003 \\
\hline 1. Patacones en circulation (stock) & 822 & 2626 & 39 \\
\hline 2. Revenus d'origine provinciale & 4083 & 4915 & 6687 \\
$1 / 2$ & $20,1 \%$ & $53,4 \%$ & $0,6 \%$ \\
\hline 3. Revenus Totaux & 7608 & 8540 & 11116 \\
$1 / 3$ & $10,8 \%$ & $30,7 \%$ & $0,3 \%$ \\
\hline 4. PBG au prix de marché & 91364 & 81411 & 88510 \\
$1 / 4$ & $0,9 \%$ & $3,2 \%$ & $0,0 \%$ \\
\hline
\end{tabular}

Source: Elaboration propre à partir de données de la Dirección Provincial de Estadística et de la Dirección Provincial de Política de Financiamiento y Crédito Público.

\subsection{L'échec du federal, province d'Entre Rios}

L'expérience de la province d'Entre Rios a été bien différente, voire même totalement à rebours de celle de Buenos Aires. Le gouvernement y fut aussi contraint d'émettre sa propre monnaie, le federal, mais le résultat a été ici loin d'être un succès, surtout pour les employés publics qui l'ont reçu en paiement de leurs salaires et qui ont constaté qu'il pouvait n'être accepté qu'à $60-70 \%$ de sa valeur nominale en peso. Cette province était gouvernée à l'époque de la circulation du federal par Sergio Montiel, "caudillo " occupant une place importante dans le Radicalisme, parti du Président de la République $^{27}$. Héritier d'une mauvaise situation budgétaire, Montiel était considéré lui aussi comme un mauvais gestionnaire. Selon Lafferrière (2004), au commencement de son deuxième gouvernement, la Province était en effet fortement endettee notamment à l'égard de la banque privée avec des échéances concentrées sur la période 2000-200328. Mais comme le montre le tableau 2, son arrivée au pouvoir en 1999 coïncide aussi avec un

27 S. Montiel en était à son deuxième mandat de Gouverneur, avec des gouvernements péronistes entre ses deux mandatures.

28 L'Entre Rios est considérée comme une province avec déséquilibre persistant des finances publiques et incapacité d'assainissement budgétaire sur 1995-2000, par Cetrangolo et alii, 2002.

36 Economie et Institutions $-\mathrm{n}^{\circ} 10$ et $11-1$ er $\& 2$ e semestre 2007 
accroissement important du déficit budgétaire de la Province. Malgré l'importance de la dette provinciale héritée, le Gouverneur a procédé à l'achat d'un avion de la flotte présidentielle et d'un hôtel cinq étoiles. Que ces dépenses aient été bien fondées ou pas, le fait que ce dernier ait par ailleurs commencé sa gestion par la mise au chômage de milliers d'employés publics a engendré le sentiment qu'elles se faisaient sur le dos des travailleurs ${ }^{29}$. D'où, comme au niveau du gouvernement fédéral dirigé par le président De la Rua, la montée d'une forte défiance à l'égard du gouvernement en place qui conduira aussi, mais pas avec le même résultat, à d'importantes manifestations de rue destinées à le faire abdiquer. Ainsi, "le contexte social dans l'Entre Rios à la mi-2001 était celui d'une crise de légitimité du gouvernement provincial, accompagnée d'une crise de la coalition au pouvoir au niveau national. L'Etat provincial avait des retards de paiements de salaires vis-à-vis de ses employés, ce qui, ajouté aux autres coupures budgétaires au niveau national et à l'émission des bons provinciaux, a engendré le développement d'un malaise profond et croissant vis-à-vis du gouvernement provincial. (...) La perte d'appui du gouvernement national et la mauvaise gestion du ministre fédéral de l'économie, Domingo Cavallo, complétaient un panorama provincial de chômage croissant, de salaires payés avec retard et d'ajustement budgétaire. Le contexte dans lequel furent lancés les bonos fut, en conséquence, un contexte de faible légitimité et de crise politique. Depuis leur tout début, la légitimité des bonos est restée liée à celle du gouverneur " (Obradovitch, 2004) ${ }^{30}$.

29 Selon le gouverneur S. Montiel, elles s'expliquent par son opposition aux politiques inspirées par le régime de convertibilité. Il n'aurait jamais accepté l'idée d'un besoin impératif d'ajustement, d'où les sauvetages par la Province d'entreprises au bord de la faillite. Quant aux licenciements, ils étaient justifiés par un besoin d'assainissement du corps des employés de la Province, vicié par le clientélisme et une mauvaise gestion du gouverneur antérieur (péroniste) (entretien avec Sergio Montiel, 13 février 2008). Dans cet entretien, celui-ci déclare également s'être farouchement opposé au pacte de "Olivos " conclu en 1993 entre le Parti radical et le péronisme au niveau national, pacte qui a permis la réélection de Carlos Menem comme président de la République.

30 Cf. aussi du même auteur "Cuando murio el peso. Los intercambios cotidianos con los bonos provinciales de Entre Rios ", version revue du même texte, communication personnelle aux auteurs.

Economie et Institutions $-\mathrm{n}^{\circ} 10$ et $11-1$ er $\& 2$ e semestre 2007 
Tableau 2 : Situation budgétaire en Entre-Rios

\begin{tabular}{|l|r|r|r|r|r|r|}
\hline & $\begin{array}{c}\text { Revenus } \\
\text { courants }\end{array}$ & $\begin{array}{c}\text { Total } \\
\text { Revenus }\end{array}$ & \multicolumn{1}{c|}{$\begin{array}{c}\text { Dépenses } \\
\text { courantes }\end{array}$} & $\begin{array}{l}\text { Total } \\
\text { dépenses }\end{array}$ & \multicolumn{1}{c|}{$\begin{array}{c}\text { Résultat } \\
\text { économique }\end{array}$} & $\begin{array}{c}\text { Résultat } \\
\text { financier }\end{array}$ \\
\hline 1989 & 438 & 439 & 391 & 448 & 47 & -9 \\
\hline 1990 & 414 & 416 & 430 & 485 & -16 & -69 \\
\hline 1991 & 526 & 529 & 512 & 570 & 14 & -41 \\
\hline 1992 & 767 & 772 & 753 & 830 & 14 & -58 \\
\hline 1993 & 874 & 878 & 822 & 915 & 52 & -37 \\
\hline 1994 & 955 & 995 & 924 & 1.035 & 31 & -40 \\
\hline 1995 & 940 & 960 & 958 & 1.156 & -18 & -196 \\
\hline 1996 & 1.039 & 1.211 & 936 & 1.051 & 103 & 160 \\
\hline 1997 & 1.134 & 1.169 & 952 & 1.194 & 182 & -25 \\
\hline 1998 & 1.169 & 1.199 & 1.021 & 1.187 & 148 & 12 \\
\hline 1999 & 1.112 & 1.167 & 1.111 & 1.351 & 1 & -184 \\
\hline 2000 & 1.103 & 1.117 & 1.174 & 1.318 & -71 & -201 \\
\hline 2001 & 1.060 & 1.089 & 1.232 & 1.356 & -172 & -267 \\
\hline
\end{tabular}

Affecté par les mauvaises performances du currency board, l'Entre Rios s'est retrouvé comme toutes les autres Provinces en manque de financement. Mais sa situation était spécifique car un grande partie de ses fonds au titre de la coparticipation avait été utilisé comme garantie des dettes contractées et, de ce fait, était retenue par l'Etat fédéral alors même que tout nouveau financement était coupé ${ }^{31}$. Du fait des critiques de l'opposition principalement péroniste concernant la gestion montiéliste, le projet de loi de création du federal, déposé au Parlement provincial le 25 juillet 2001, n'a été finalement approuvé que le $1^{\mathrm{er}}$ octobre avec d'importantes modifications: les montants d'émission ont été abaissés d'un total de 450 millions à 100 millions de pesos, réduction compensée par l'autorisation de créer un deuxième bon destiné à payer les fournisseurs de la Province à hauteur de 170 millions de pesos, le certificado. Toutefois aucun certificado ne sera produit, et le gouvernement n'émettra que des federales. Une Caisse de conversion est créée par la même loi, caisse destinée à assurer la parité entre le federal et le peso, les personnes désirant changer leurs federales contre des pesos pouvant s'y présenter dans certaines conditions (elle était destinée à servir pour les seules dépenses à l'extérieur de la province).

31 «(...) il est probable qu'en 2002, les deux tiers des ressources de l'Entre Rios correspondant à la coparticipation n'arrivent pas à destination, car elles doivent être transférées aux créanciers de la Province " (El Diario du 29/10/2001). Cela dit, celles-ci ne représenteraient que le tiers de l'ensemble des transferts fédéraux à la Province (Piffano, 2004, p. 22).

38 Economie et Institutions - n 10 et $11-1$ er \& 2e semestre 2007 


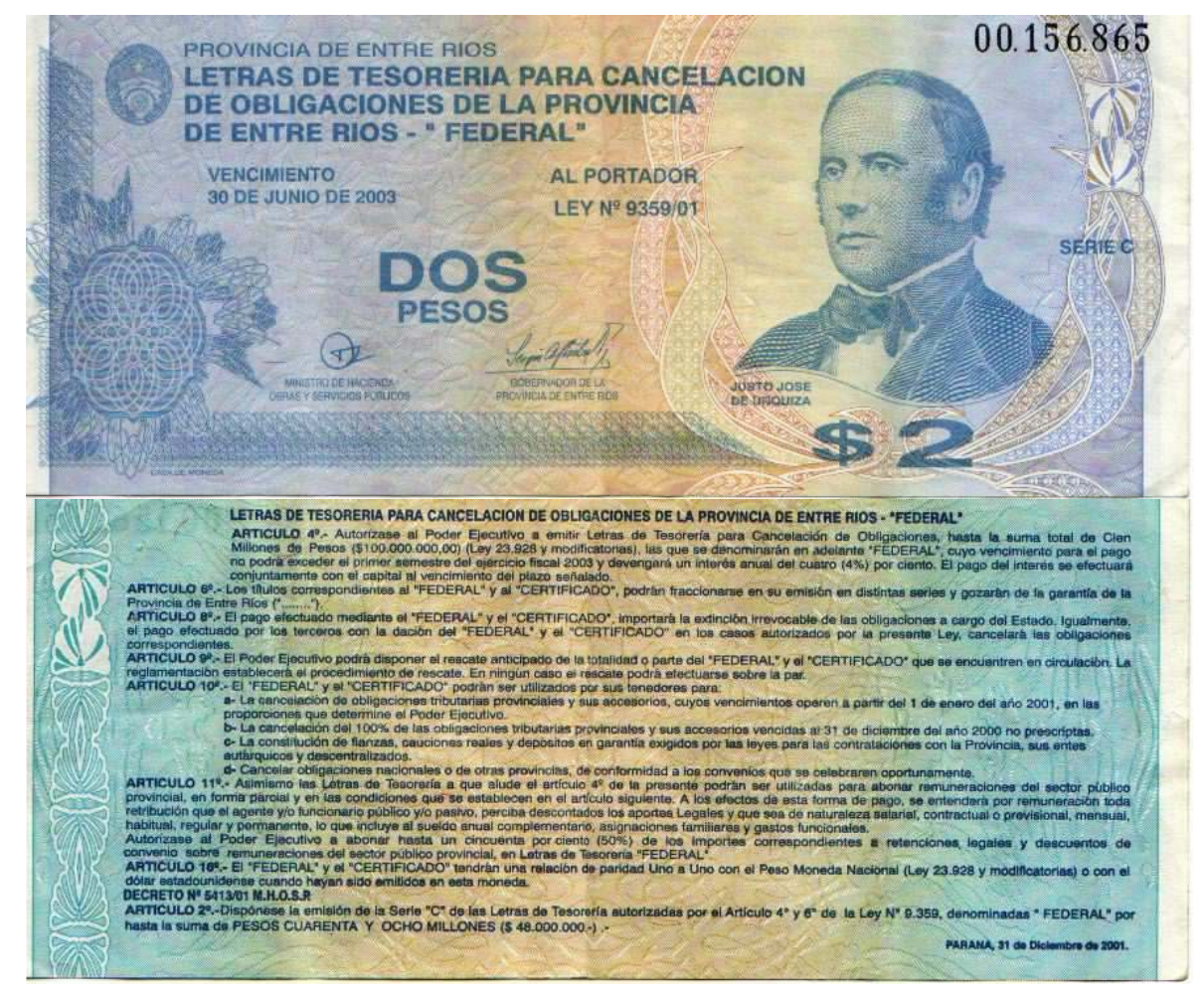

L'espoir que le federal soit accepté à l'extérieur de la province n'a pas en effet résisté à l'échec de la négociation avec la Nacion (l'Etat fédéral) pour qu'il soit comme le patacon admis en paiement des impôts fédéraux. Et, étant donnée la structure productive de la province, " exportatrice " de produits primaires et "importatrice " de produits manufacturés, l'accord s'est fait pour considérer que le commerce avec le reste de l'Argentine devait se faire soit en pesos, soit en lecop, ce qui impliquait une conversion des federales en pesos. Or pour garantir dès le départ de sa mise en circulation l'acceptation du federal à la parité, cette conversion ne pouvait être laissée au marché. La Caisse de conversion devait donc fournir ces pesos et lecops. 
Enfin, un accord signé avec la BERSA (Banque d'Entre Rios Société Anonyme) visait à établir un circuit monétaire pour les federales. Mais cette banque privatisée ne disposait pas d'un réseau de succursales et de caisses très important, et cela d'autant moins qu'elle avait subi des restructurations drastiques avant et après sa privatisation de façon à la rendre profitable et similaire à une banque privée $^{32}$.

Durant un premier temps, de la première mise en circulation le 9 novembre 2001 (émission réduite à 100 millions de pesos) jusqu'à juin 2002, le système fonctionne correctement, car le federal est alors vu par une grande partie de la population comme un outil regrettable mais néanmoins nécessaire pour faire face à la crise. Les discussions ne portent alors que sur les pourcentages des achats qu'il est possible de payer avec cette monnaie, et non pas sur sa parité avec le peso ${ }^{33}$. Ainsi le federal est accepté au pair, notamment grâce à la garantie de la Caja de conversion qui, bien que mise en place avec retard (elle n'entre en action que le 17 décembre 2001), fonctionne d'abord correctement sans accumuler de dettes d'importance (cf. graphique 6).

32 "Pour résumer, les données disponibles indiquent que les banques provinciales privatisées étaient beaucoup plus semblables aux dix plus grandes banques privées d'Argentine qu'aux banques provinciales publiques. D'abord, comme pour les banques privées, leur profitabilité et efficacité proviennent désormais légèrement plus de leurs revenus financiers nets que des services qu'elle fournissent. (...) Leur meilleure situation se reflète dans la qualité de leur portefeuille. Cette amélioration de la qualité de leur portefeuille coincide avec la décroissance de leurs engagements en termes de crédit public. Tout ceci augure bien de la future solvabilité de ces banques " (Clarke et Cull, 1999). Il est ainsi frappant de constater qu'à la date du 3 janvier 2002, la BERSA, agent financier de la Province gérant la mise en circulation du federal et intermédiaire de la Caisse de conversion, refusait tant le federal que la lecop pour tout paiement de ses services bancaires ( $E l$ Diario du 3/01/2002)! Il est vrai qu'elle était dans des mains étrangères, françaises plus précisément, celles de la Caisse Nationale de Crédit Agricole. 33 Il est même accepté à la parité (à concurrence de 50 voir $100 \%$ de la valeur des achats) dans un nombre significatif de commerces de Santa Fé, capitale voisine de la province du même nom qui n'a pas, quant à elle, émis de monnaie provinciale (El Diario du 10/03/2002).

40 Economie et Institutions - n 10 et $11-1$ er \& 2e semestre 2007 


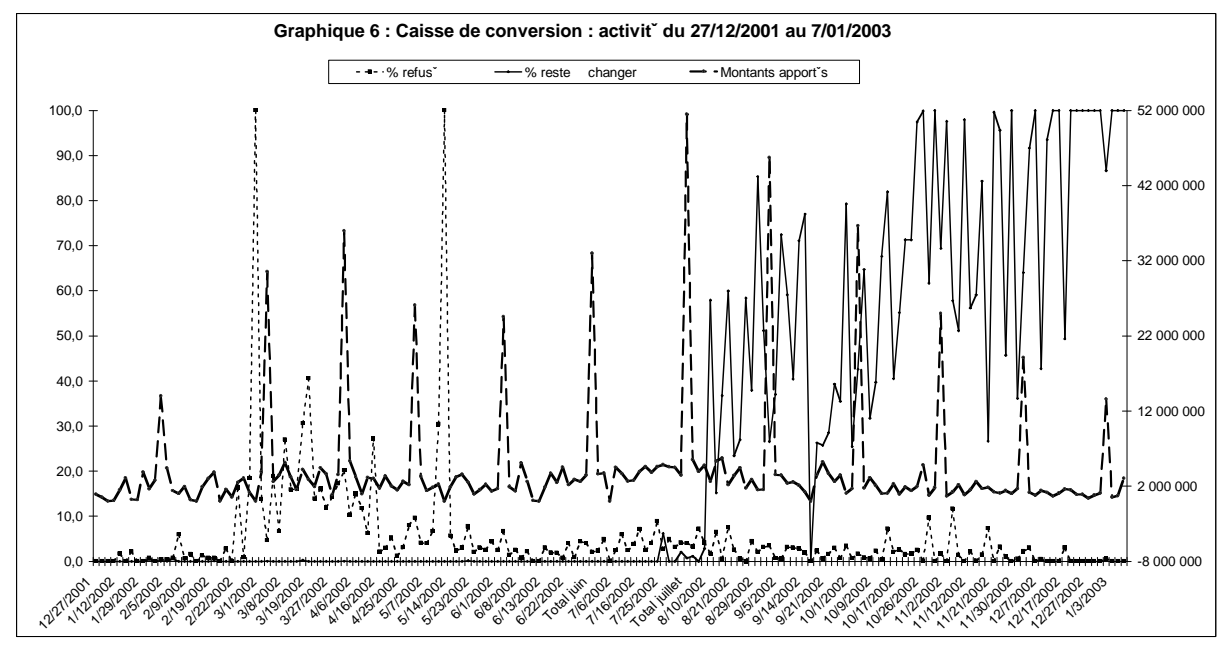

Sources : Archives personnelles de Mr Osvaldo Cepeda ${ }^{34}$

Par ailleurs, l'Assemblée multisectorielle des petites et moyennes entreprises (APYME), très active pendant la crise, ne s'est pas opposée à la nouvelle monnaie ni au gouvernement pendant cette première période ${ }^{35}$. Pourtant les négociations entre le gouvernement et le secteur privé ne semblent avoir eu ni l'ampleur ni la systématicité qu'elles ont eu dans la Province de Buenos Aires. De nos entretiens avec des acteurs de premier rang de ces négociations, il ressort qu'ils se sont montrés beaucoup moins fermes avec les grandes entreprises que leurs collègues de Buenos Aires, notamment avec les entreprises privatisées de fourniture d'électricité. Cette "faiblesse " est paradoxalement allée de pair avec des tentatives conflictuelles d'imposer de manière compulsive, via diverses lois

34 Il nous faut remercier Osvaldo Cepeda, ministre des finances de l'Entre Rios qui a présidé à la mise en place du federal, pour nous avoir accordé un long entretien, donné accès à ses archives, et précisé par écrit ses réponses à certaines de nos questions. Dans la courbe relative aux federales apportés à la Caisse pour être changés en pesos au pair, les pointes correspondent aux montants cumulés mensuels alors que les autres données concernent des opérations journalières. Jusqu'en juillet, il n'y a quasiment pas de dette de change, la Caisse jouant plutôt, surtout en mars 2002, du rejet des demandes de change, celles-ci devant être appuyées par des preuves avérées des paiements à effectuer à l'extérieur de la province et par des preuves de l'acceptation des federales à $100 \%$ de la part des commerces demandeurs ( $E l$ Diario du 10/12/2001).

35 Entrevue avec Alfredo Caino, secrétaire de l'APYME, association des petites et moyennes entreprises, délégation Parana, 11 novembre 2005.

Economie et Institutions $-\mathrm{n}^{\circ} 10$ et $11-1$ er $\& 2$ e semestre 2007 
d'urgence, la réception des federales à au moins 50\% du montant des paiements d'abord, puis à $100 \%$.

Comme le montre le graphique 6, c'est à partir de juillet 2002, après l'émission controversée, voire forcée par le gouverneur, d'une troisième série de federales, trois fois plus volumineuse que les deux précédentes réunies, que 1a Caisse de conversion a commencé à accumuler des dettes de change ${ }^{36}$. Dès lors, des accusations de favoritisme dans l'échange des monnaies se sont mêlées à d'autres plus graves de corruption. D'où une perte de crédibilité de la Caisse qui aurait pu à elle seule miner la valeur du federal. Il faut, néanmoins, y ajouter le conflit de pouvoir entre l'exécutif et le législatif qui s'est exacerbé à partir de mars 2002 lorsque le Gouverneur demande au Parlement provincial l'autorisation de faire la nouvelle émission. Cette dispute s'est intensifiée quand le Gouverneur a décidé à la mi-mai de l'instituer par décret. L'absence de légalité de cette mesure semble avoir fait basculer la balance en faveur de l'opposition. A partir de là, le refus d'acceptation du federal s'est amplifié pour des raisons autant politiques qu'économiques.

$\mathrm{Vu}$ le fonctionnement de plus en plus défaillant et discriminatoire de la Caisse de conversion, celle-ci manquant de liquidité en monnaies nationales (peso et lecop), les commerçants ont accentué leur recours aux arbolitos, les changeurs de monnaies au noir, afin d'obtenir des pesos pour payer leurs fournisseurs et leurs impôts nationaux. D'une commission estimée à $15 \%$ fin janvier 2002 sur sa valeur nominale (taux relativement faible vu les taux d'intérêt du moment (au plus fort de la crise de la convertibilité), on est passé à une décote du federal beaucoup plus importante. Les journaux ont commencé à parler de différences de prix selon la monnaie de paiement à partir de mai 2002 (El Diario du 05/05/2002) et, en octobre, les commerçants affichaient les prix simultanément en pesos et, avec décote, en federales. Au fur et à mesure que le federal perdait de sa valeur, la perception grandissait qu'il s'agissait plus d'un outil de prélèvement que d'une représentation synthétique de défense des valeurs de la communauté provinciale. Ainsi les groupes

36 "C'est dire que l'instrument avait en germe dans sa propre genèse la dévalorisation de son taux de change, et si dans l'Entre Rios, celle-ci fut supérieure à celles que connurent d'autres provinces, je pense comme les économistes dont on vient de parler que cela se doit en partie à la quantité émise, conséquence d'un plus grand déficit de financement que dans ces autres provinces, et à l'impossibilité de maintenir le change automatique des federales en pesos via la caisse de conversion comme dans les premiers six mois de son fonctionnement, conséquence quant à elle de la diminution des recettes au titre de la coparticipation fédérale due à l'exécution des garanties bancaires signées par les gouvernements antérieurs avec des taux d'intérêt annuels qui sont montés jusqu'à 40 \% à cette occasion "(Cepeda, 2006).

42 Economie et Institutions $-\mathrm{n}^{\circ} 10$ et $11-1$ er \& 2e semestre 2007 
qui appuyaient ou ne s'opposaient pas jusque là au federal ont commencé à réclamer directement l'assistance de la Nacion dans un contexte de perte de légitimité accrue du gouvernement provincial affectant la confiance dans " sa " monnaie. S'est de la sorte créé un cercle vicieux dans lequel une perte de légitimité politique conduisait à une perte de valeur de la monnaie qui détériorait encore plus la situation politique du gouvernement et donc, derechef, la confiance dans sa monnaie.

En fait, malgré le relatif succès de sa première émission, le federal n'a jamais été pour les entrerrianos ${ }^{37}$ "leur " monnaie, sinon la monnaie du gouvernement et d'un gouvernement, qui plus est, souffrant d'un important déficit de légitimité. Le seul fait qu'il n'ait pas respecté d'entrée de jeu les pourcentages de federales et de pesos qui devaient être versés selon les niveaux des salaires (cf. tableau 3) augurait mal de son avenir en mettant d'emblée en cause la parole de l'Etat provincial. Le conflit qui, au début de sa création, oppose l'exécutif et le législatif entamait également d'emblée sa légitimité.

Dans ces conditions, il était très difficile d'assurer une confiance hiérarchique dans la nouvelle monnaie. La question se pose néanmoins de savoir si un soutien du gouvernement fédéral à l'administration Montiel sous la même forme que pour le patacon (acceptation du federal pour le paiement des impôts fédéraux) aurait pu rendre l'expérience plus réussie ${ }^{38}$. Toutefois cette interrogation ne fait sens que si on se pose la question préalable du pourquoi ce soutien n'a pas été donné alors que le gouvernement provincial était de la même couleur politique que le gouvernement fédéral et que l'opposition parlementaire péroniste dans la province était très forte et acrimonieuse.

Notre enquête ne nous a pas encore permis de répondre complètement à cette question, mais nous pouvons faire plusieurs hypothèses. On peut d'abord considérer que les prises de position quant à la légitimité des monnaies provinciales sont transpartidaires: le patacon est péroniste et soutenu par l'opposition radicale ; le federal est radical et attaqué par l'opposition péroniste ; la lecor est péroniste mais s'inscrit dans la continuité du cecor radical.

37 Les habitants de la province de l'Entre-Rios.

38 Sans qu'il s'agisse nécessairement d'une condition nécessaire de la confiance dans une monnaie provinciale, comme en témoigne l'expérience de la lecor dans la Province de Cordoba.

Economie et Institutions $-\mathrm{n}^{\circ} 10$ et $11-1$ er $\& 2$ e semestre 2007 
Tableau 3 : Différences dans la construction du patacon et du federal

\begin{tabular}{|c|c|c|}
\hline Types de confiance & patacón & federal \\
\hline $\begin{array}{l}\text { Différences dans la } \\
\text { construction de la } \\
\text { confiance méthodique }\end{array}$ & $\begin{array}{l}\text { Plan de négociations } \\
\text { systématiques avec le secteur } \\
\text { privé. } \\
\text { On peut payer ses impôts } \\
\text { nationaux en patacon }\end{array}$ & $\begin{array}{l}\text { Conversations « tièdes » avec } \\
\text { le secteur privé. } \\
\text { Le federal n'est pas accepté } \\
\text { pour payer les impôts } \\
\text { nationaux }\end{array}$ \\
\hline $\begin{array}{l}\text { Différences dans la } \\
\text { construction de la } \\
\text { confiance éthique }\end{array}$ & $\begin{array}{l}\text { Règle d'émission relative aux } \\
\text { destinataires primaires : } \\
\begin{array}{l}\text { Salaires > } 740 \text { pesos payés en } \\
\text { patacones }\end{array} \\
\text { Respectée } \\
\text { Le patacon s'inscrit bien dans } \\
\text { l'imaginaire politico-symbolique } \\
\text { bonaerense }\end{array}$ & $\begin{array}{l}\text { Règles d'émission relatives aux } \\
\text { destinataires primaires : } \\
350<\text { Salaires }<700 \text { pesos : } \\
350 \text { pesos + solde en federales; } \\
\text { salaires > } 700 \text { pesos : } 50 \% \text { en } \\
\text { federal. } \\
\text { Jamais respectées, tous les } \\
\text { salaires payés à } 100 \% \text { en } \\
\text { federales } \\
\text { Le federal s'inscrit mal dans } \\
\text { l'imaginaire politico- } \\
\text { symbolique entreriano }\end{array}$ \\
\hline $\begin{array}{l}\text { Différences dans la } \\
\text { construction de la } \\
\text { confiance hiérarchique }\end{array}$ & $\begin{array}{l}\text { Règles monétaires claires. } \\
\text { Acceptation politique } \\
\text { transpartidaire. } \\
\text { L'Etat fédéral garantit la } \\
\text { circulation interprovinciale du } \\
\text { patacon au même titre que celle } \\
\text { de sa propre monnaie fiscale, la } \\
\text { lecop. } \\
\text { Banque provinciale publique et } \\
\text { au réseau étendu. Circuit du } \\
\text { Trésor large. }\end{array}$ & $\begin{array}{l}\text { Autorité du Gouverneur } \\
\text { contestée. Mauvaise situation } \\
\text { politique interne et externe. } \\
\text { Conflit entre partis politiques. } \\
\text { Mauvaise perception de la } \\
\text { gestion budgétaire. } \\
\text { Création d'une «caisse de } \\
\text { conversion» qui fonctionne mal } \\
\text { à partir de juin 2002. } \\
\text { Banque provinciale privatisée } \\
\text { et au réseau réduit. Peu de } \\
\text { correspondants du Trésor }\end{array}$ \\
\hline
\end{tabular}

Sur cette base, on peut supposer que le refus d'accorder au federal le même privilège qu'au patacon, à savoir la possibilité de s'en servir pour payer des impôts fédéraux, renvoie d'une part à la volonté du gouvernement fédéral de ne pas entériner la mauvaise gestion du gouverneur Montiel ; d'autre part au fait que le gouvernement fédéral pouvait craindre de se retrouver avec plus de federales qu'il ne pourrait en retourner à la province, compte tenu qu'une grande partie des ressources de coparticipation de l'Entre Rios servait à payer ses dettes accumulées et que cette Province disposait de peu d'autonomie fiscale ${ }^{39}$; enfin au fait que le gouvernement fédéral ne voulait pas généraliser le privilège du patacon dans le mesure où il s'était lui-même mis à émettre une monnaie fiscale, la lecop, destinée

$39 \mathrm{Cf}$. le ratio (transferts fédéraux à la province)/(impôts fédéraux payés par la province) dans le tableau 6 infra.

44 Economie et Institutions - n 10 et $11-1$ er \& 2e semestre 2007 
aux paiements entre Provinces et Nacion (et qui devait aussi au départ se substituer au patacon). Mais on peut aussi poser une hypothèse plus politique concernant la concurrence entre le Président De La Rua et le Gouverneur Montiel au sein du Parti radical.

C'est à défaut d'un tel soutien fédéral pour fonder la confiance méthodique dans le federal, que le ministre des finances de la Province, Osvaldo Cepeda, qui dit s'être inspiré de l'expérience de la première Caisse de conversion de l'Argentine mise en place par Carlos Pellegrini en 1890, a mis sur pied une telle caisse instituant hors marché la convertibilité au pair entre le federal et le peso. Comme on l'a vu, cette institution a bien fonctionné tant que l'émission de federal est restée proportionnée aux possibles recettes en pesos et lecops de la Province mais, de manière classique, elle deviendra le talon d'achille du système quand elle sera sousfinancée et, dès lors, sujette au jeu de la corruption et/ou utilisée de manière clientéliste. Si on en vient enfin aux dimensions éthiques de la confiance, ce qui ressort est à nouveau en ce cas une situation à l'opposé de celle prévalant dans la province de Buenos Aires. Ce contraste renvoie en fait à l'histoire longue des deux provinces et à la place très différente qu'a joué l'unification monétaire à l'échelle de la Nacion dans leurs imaginaires institués respectifs, toutes deux ayant eu un rôle central à l'opposé l'une de l'autre dans l'unification du pays. Ceci est transparent dans le discours du ministre Cepeda qui, bien que créateur du federal, fait ressortir que les conditions éthicosymboliques dans l'Entre Rios étaient a priori défavorables à son succès, discours qui contraste avec le côté conquérant des promoteurs du patacon et le slogan "je suis argentin, j'accepte le patacon ${ }^{40}$.

Ainsi le créateur du federal peut-il dire en réaction au texte d'Obradovitch précité :

" Enfin j'ajouterai comme facteur de dévaluation du federal la qualité et l'intégrité sociale de la communauté d'Entre Rios, qui n'a rien à voir avec celle de Tucumán, La Rioja, ou Catamarca par exemple où le caudillisme politique a habitué la population à être pauvre et dépendante du pouvoir politique ${ }^{41}$. L'Entre Ríos, je pense, maintient encore en haute estime, sans distinction de couleurs politiques partidaires, ses valeurs patriotiques et culturelles originaires, qui l'aidèrent à organiser la Nación argentina. Ce qui fait que naturellement toute situation qui tend à perturber son intégrité

40 Effectivement le patacon a circulé dans tout le pays au même titre que la lecop fédérale. Il a eu notamment le statut de monnaie provinciale complémentaire dans la province de Jujuy.

41 Rappelons qu'à Tucuman et à La Rioja circulaient des bonos depuis 1985, et à Catamarca depuis 1993 (Clarin, 15/11/2001).

Economie et Institutions $-\mathrm{n}^{\circ} 10$ et $11-1$ er $\& 2$ e semestre 2007 
sociale est rejetée de toute manière. Les bonos étaient indubitablement un remède très fort à une crise très forte, mais il est évident que personne ne désirait les émettre et avoir à les utiliser. (...) Entre Ríos est une province d'intégration sociale élevée qui est le berceau de l'organisateur national, Justo José de Urquiza, lequel, dans la première constitution nationale de 1853 institua l'unification monétaire de la Nación pour mettre fin à l'anarchie qui régnait à son époque et qui s'est répétée en 2002, constituant ainsi un retour en arrière inacceptable pour les entrerrianos" (Cepeda, 2006).

En d'autres termes, la culture historico-politique de l'Entre Rios, ses valeurs de référence constituaient un obstacle éthique à l'acceptation du federal, car l'idée d'une monnaie nationale unique à l'échelle du pays tout entier y est fondatrice de l'identité de la province dont la capitale, Parana, fut un temps celle de la Fédération.

En résumé, l'expérience du federal montre comment l'émission d'une nouvelle monnaie peut synthétiser les peurs et méfiances de toute une collectivité, le moment venu. Elle montre aussi la variété possible des constructions institutionnelles des monnaies fiscales provinciales et, par comparaison avec celle du patacón, aide à circonscrire un certain nombre de conditions de viabilité de telles expériences.

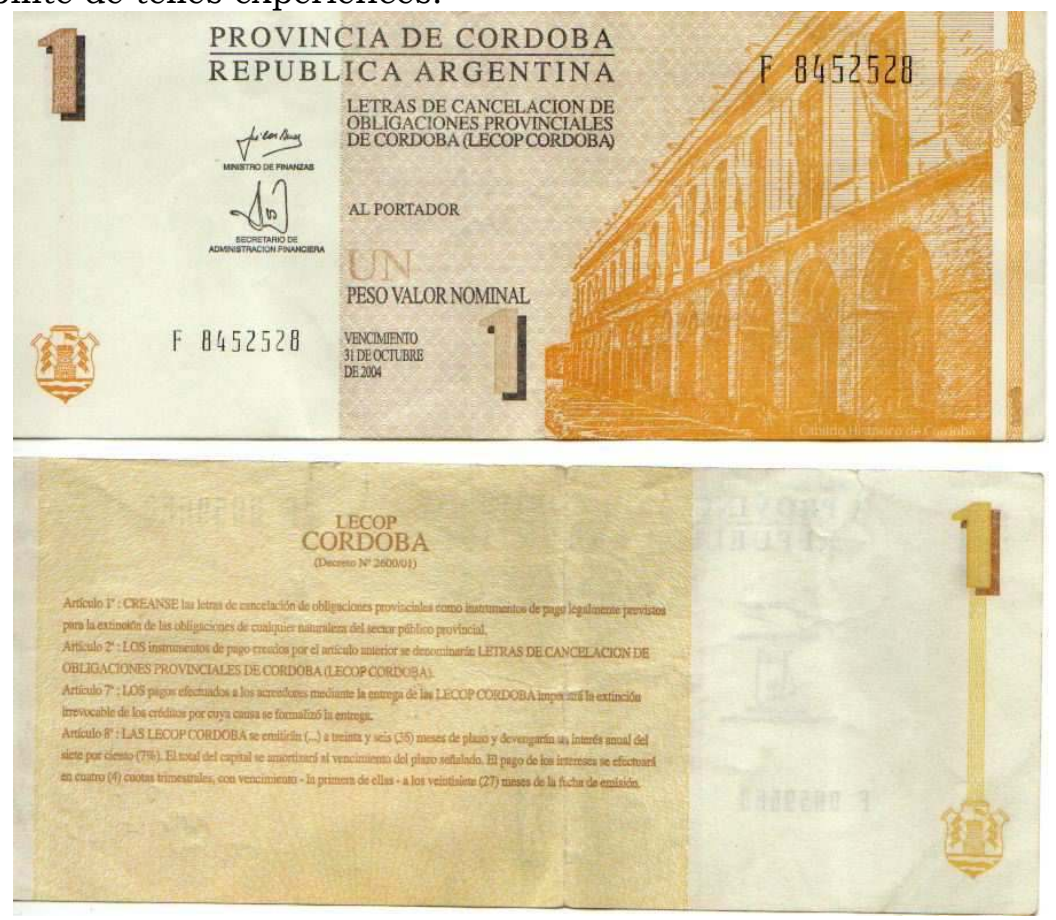

46 Economie et Institutions $-\mathrm{n}^{\circ} 10$ et $11-1$ er \& 2e semestre 2007 


\section{Les conditions de viabilité des monnaies fiscales provinciales : montée en généralité par élargissement de la comparaison aux provinces de Cordoba, Corrientes et Santa Fé}

Les expériences argentines de monnaies provinciales invitent à effectuer un exercice contrefactuel consistant à se demander quelles auraient été les préconditions nécessaires, en termes d'accords fiscal et monétaire entre les Provinces et la Nacion, permettant d'assurer la cohabitation au pair de ces diverses monnaies nationales et provinciales. La confrontation des expériences (élargie à la lecor - Cordoba - et au cecacor - Corrientes ainsi qu'à un cas d'absence de monnaie provinciale dans la province de Santa Fé, par ailleurs similaire à celle de Cordoba), peut permettre d'avancer dans cette direction. Elle conduit, en effet, à mettre à jour certaines régularités à partir desquelles il est possible de poser quelques hypothèses pour un développement de la recherche sur la viabilité de tels systèmes à monnaies plurielles ${ }^{42}$. On distinguera dans cette perspective les conditions économiques et politico-symboliques d'une telle viabilité.

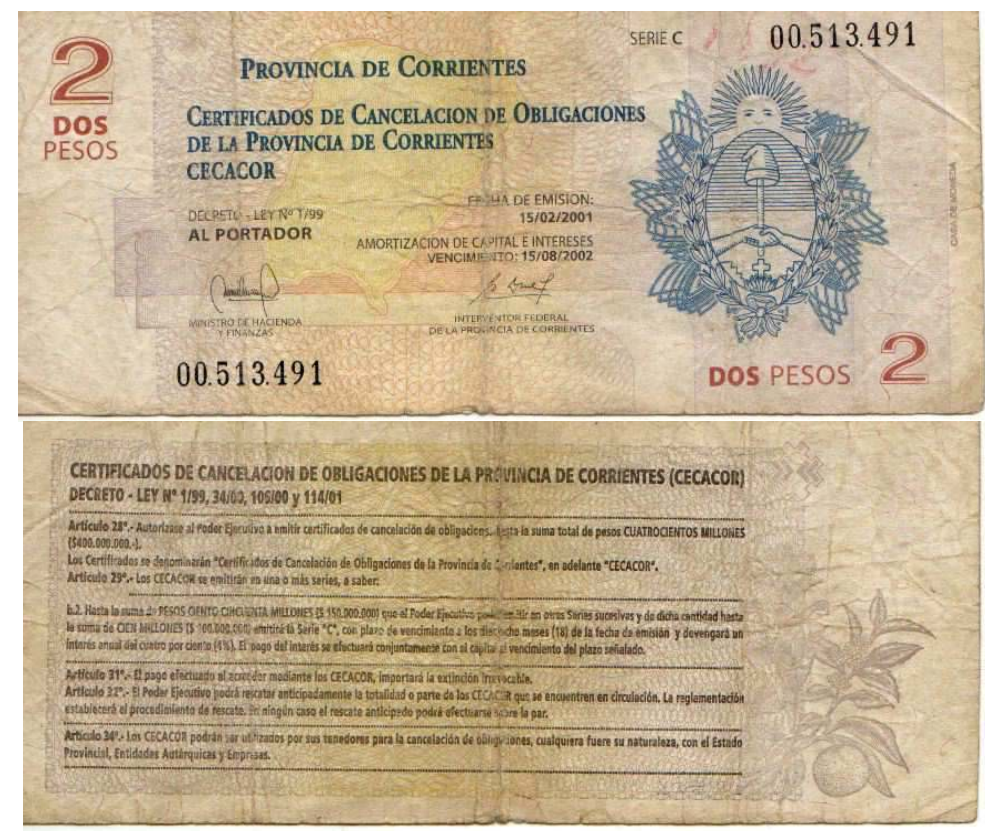

42 Les quatre provinces émettrices retenues sont celles qui ont fait les plus grosses émissions Ces émissions représentent $85-86 \%$ du total en août 2002. Si on y ajoute la Province de Tucuman, la 5ème plus forte émission, on atteint $88-89 \%$ du total.

Economie et Institutions $-\mathrm{n}^{\circ} 10$ et $11-1$ er $\& 2$ e semestre 2007 


\subsection{Préconditions économiques et financières}

Le graphique 7 regroupe pour les cinq provinces sous revue une série d'indicateurs économiques dont la juxtaposition permet de figurer en quelque sorte les tailles relatives du socle économique - ou de la surface économique de confiance - conditionnant ou facilitant l'émission de monnaies provinciales viables. Ce graphique est construit de manière à ce que les valeurs les plus élevées (en 2001) indiquent des degrés a priori supérieurs de viabilité potentielle de telles monnaies. Il en ressort un classement des conditions économiques supposées les plus favorables à l'émission de monnaies provinciales viables.

La Province de Santa Fé est celle où cette capacité apparaît la plus élevée, car elle dispose d'un PIB régional (PBG) par habitant élevé, est beaucoup moins endettée que les autres Provinces tout en possédant un circuit fiscal propre de taille significative ; elle possède également un degré d'industrialisation qui permet de supposer une plus grande intégration de son économie et donc un moindre besoin de monnaie convertible pour commercer avec les autres provinces. Enfin elle se caractérise par un niveau élevé de ses exportations hors Argentine (quasiment le double de sa jumelle, la Province de Cordoba, également deux fois plus endettée qu'elle) qui lui assure les devises nécessaires pour équilibrer sa balance des paiements avec l'extérieur. Cette dernière caractéristique, ainsi que son plus bas niveau d'endettement public, expliquent que cette Province ait réussi à survivre dans la crise sans émettre de monnaie propre, dans un contexte idéologique où l'unicité monétaire est la norme politique ${ }^{43}$.

43 Mais il faudrait poursuivre l'enquête pour savoir si le fait que la banque provinciale y était privatisée n'a pas été un facteur important de cette non décision.

48 Economie et Institutions $-\mathrm{n}^{\circ} 10$ et $11-1$ er $\& 2$ e semestre 2007 


\section{Graphique 7 : Socles économiques de viabilité des monnaies provinciales}

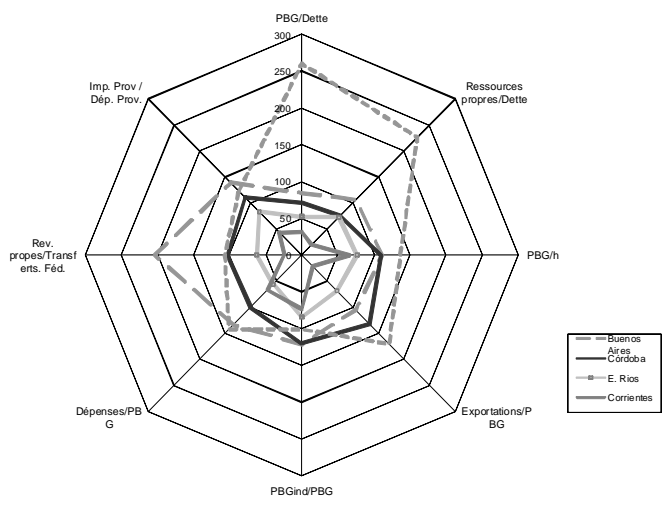

Source : Elaboration propre à partir de données du Ministère de l'Economie et des Directions provinciales de statístiques

Viennent ensuite, selon un ordre décroissant correspondant aux taux de change de leurs monnaies en pesos (graphique 8), la Province de Buenos Aires, celle de Cordoba, celle de l'Entre-Rios, puis celle de Corrientes. Cela dit, si on multiplie les indicateurs comparatifs de cet ensemble de provinces, relatifs à des données démographiques, économiques et monétaro-financières (tableau 4), on observe non plus une continuité mais plutôt une distinction marquée entre, d'un côté, les deux Provinces ayant émis des monnaies viables (Buenos Aires et Cordoba) et, de l'autre celles qui ont émis des monnaies non viables (Entre Rios et Corrientes).

Ainsi les premières sont de niveaux de développement économique sensiblement identiques à celui de la Province de Santa Fé, tandis que les secondes sont nettement moins riches au plan économique. Les premières représentent une part importante de la population et de l'économie productive argentines, les secondes une part faible. Cette différence se retrouve en matière de degrés d'ouverture économique, de taille des circuits du Trésor et de taux de dépendance vis-à-vis des transferts fiscaux de la Nacion ainsi que de niveaux d'endettement par habitant ou rapporté au PIB provincial. A 
cela il faut ajouter une différence quant aux privatisations réalisées qui, quant à elles, conditionnent pour partie l'organisation institutionnelle des circuits du Trésor des Provinces. D'une part, en effet, le fait de pouvoir compter sur une banque provinciale publique - cas des Provinces de Buenos Aires et de Cordoba au contraire de l'Entre Rios où cette banque a été privatisée - est un élément d'importance pour l'implantation effective et l'administration à moindres frais d'un circuit monétaire fiscal provincial. D'autre part, la privatisation des services publics de base, qui ont vocation à être des correspondants du Trésor clefs, s'est également révélée être un problème d'importance pour la circulation des monnaies provinciales. Dans les provinces où elle a eu lieu, les entreprises privatisées exigeaient des paiements en monnaie nationale (excepté dans la province de Buenos Aires où les impôts nationaux pouvaient être payés en patacon), ce qui a réduit d'autant le pouvoir libératoire des monnaies provinciales et donc leur capacité à s'échanger au pair en pesos.

\section{Graphique 8 : Taux de change sur le marché des monnaies provinciales}

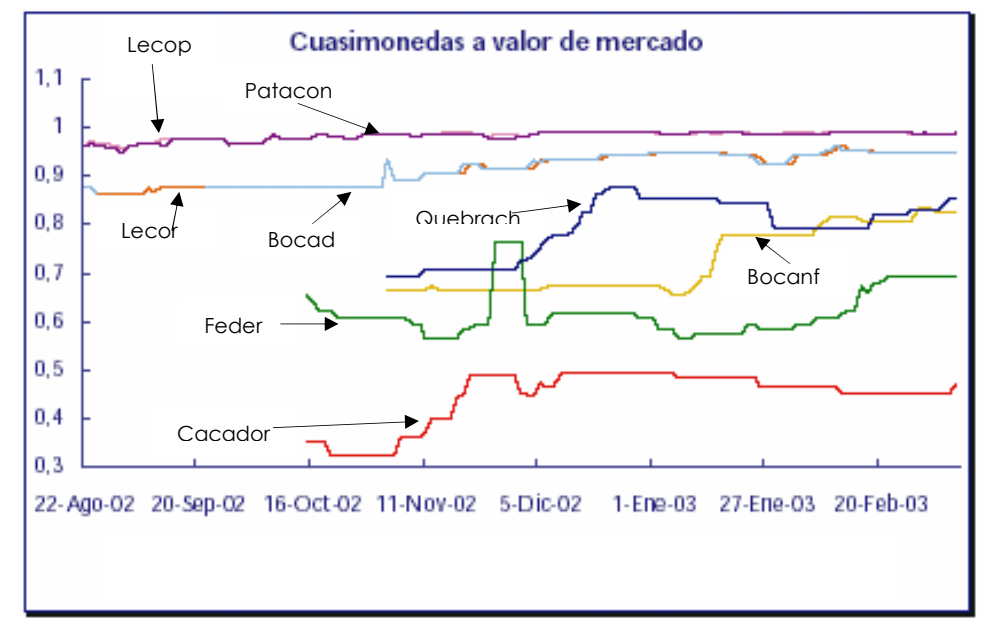

Source: Boletín Monetario mensual, BCRA, février 2003

En revanche, l'hypothèse " populiste " couramment avancée d'une part excessive des dépenses publiques de personnel permettant de distinguer des provinces vertueuses ou non, ne tient guère. En effet, la Province de Santa Fé, classée comme vertueuse du point de vue de sa gestion fisco-financière, fait partie des plus dispendieuses en ce domaine. Par ailleurs, l'emploi public supérieur dans les provinces plus pauvres, les plus suspectes de clientélisme, apparaît compensé par un coût unitaire de ces emplois plus faible.

50 Economie et Institutions - n ${ }^{\circ} 10$ et $11-1$ er $\& 2$ e semestre 2007 
Tableau 4 : Indicateurs démographiques, économiques et monétarofinanciers

\begin{tabular}{|c|c|c|c|c|c|}
\hline $\begin{array}{l}\text { Monnaie provinciale } \\
\text { Province }\end{array}$ & $\begin{array}{c}\text { Patacon } \\
\text { Buenos Aires }\end{array}$ & $\begin{array}{c}\text { Lecor } \\
\text { Cordoba }\end{array}$ & $\begin{array}{l}\text { No bonos } \\
\text { Santa Fé }\end{array}$ & \begin{tabular}{|c} 
Federal \\
Entre Rios
\end{tabular} & \begin{tabular}{|c|} 
Cecacor \\
Corrientes
\end{tabular} \\
\hline Parité / peso & $0,99-0.98$ & $0,95-0,96$ & & $0.6-0,72$ & $0,49-0.52$ \\
\hline \begin{tabular}{|l|} 
Population (2001) \\
\end{tabular} & & & & & \\
\hline En millions & 13,32 & 3,06 & 3,0 & 1,15 & 0,93 \\
\hline En $\%$ population nationale & 36,8 & 8,5 & 8,3 & 3,2 & 2.6 \\
\hline \%population âge $<15$ ans & 27 & 26 & 29 & 29 & 32 \\
\hline$\%$ population rurale & 5 & 13 & 12 & 20 & 22 \\
\hline Superficie en $\mathrm{km} 2$ & 307571 & 165321 & 133000 & 78781 & 88199 \\
\hline Densité (hab/km2) & 43 & 19 & 23 & 15 & 11 \\
\hline \begin{tabular}{|l|} 
Mortalité infantile \\
\end{tabular} & 15,1 & 15,0 & 14,4 & 16,9 & 30,4 \\
\hline $\begin{array}{l}\text { Macroéconomie (2001) } \\
\text { - PBG / tête (pesos) } \\
\text { - \% moyenne nationale } \\
\text { - PBG : \% total national } \\
\text { - PBG 2000/ PBG } 1993 \\
\text { - Indicateur de sous-développement relatif }{ }^{44}\end{array}$ & $\begin{array}{c}6161 \\
86,9 \\
33,14 \\
1,075 \\
162\end{array}$ & $\begin{array}{c}6693 \\
94,4 \\
7,98 \\
1,068 \\
172\end{array}$ & $\begin{array}{c}6490 \\
91,5 \\
7,57 \\
1,053 \\
166\end{array}$ & $\begin{array}{c}4994 \\
70,4 \\
2,25 \\
1,076 \\
193\end{array}$ & $\begin{array}{c}3107 \\
43,8 \\
1,12 \\
0,914 \\
261\end{array}$ \\
\hline $\begin{array}{l}\text { Degré d'ouverture } \\
\text { - \% PBG exporté : } 2000 ; 2002 \\
\text { - \% exports nationales }\end{array}$ & $\begin{array}{c}12,3 ; 15,4 \\
48\end{array}$ & $\begin{array}{c}12,3 ; 17,5 \\
9,3\end{array}$ & $\begin{array}{c}23,4 ; 28,1 \\
17,4\end{array}$ & $\begin{array}{c}3,4 ; 9,5 \\
0,7\end{array}$ & $\begin{array}{c}3,3 ; 3,7 \\
0,4\end{array}$ \\
\hline $\begin{array}{l}\text { Taille circuit du Trésor (2001 et en \%) } \\
\text { - Impôts prov. / dépenses } \\
\text { - Dépenses prov./ PBG } \\
\text { - Part de la Province dans les ressources } \\
\text { nationales }\end{array}$ & $\begin{array}{c}35 \\
12,4 \\
22,5\end{array}$ & $\begin{array}{c}28 \\
13,2 \\
8,1\end{array}$ & $\begin{array}{c}31 \\
12,4 \\
8,1\end{array}$ & $\begin{array}{c}21 \\
21,2 \\
4,6\end{array}$ & $\begin{array}{c}11 \\
25,2 \\
3,7\end{array}$ \\
\hline $\begin{array}{l}\text { Indépendance / transferts fédéraux } \\
-\% \text { ressources propres } \\
\text { - \% coparticipation }\end{array}$ & $\begin{array}{l}48 \\
29\end{array}$ & $\begin{array}{l}29 \\
32\end{array}$ & $\begin{array}{l}32 \\
26\end{array}$ & $\begin{array}{l}23 \\
28\end{array}$ & $\begin{array}{l}16 \\
44\end{array}$ \\
\hline $\begin{array}{l}\text { Degré d'arbitraire des transferts fédéraux } \\
\text { - Absolu (copart./total) } \\
\text { - Relatif (abs / moy. nat) } \\
\end{array}$ & $\begin{array}{l}0,44 \\
0,82\end{array}$ & $\begin{array}{c}0,55 \\
1,0\end{array}$ & $\begin{array}{l}0,62 \\
1,15\end{array}$ & $\begin{array}{l}0,66 \\
1,23\end{array}$ & $\begin{array}{l}0,48 \\
0,88\end{array}$ \\
\hline \begin{tabular}{|l|} 
Répartition de la lecop \\
Part Province / total émis \\
Rapporté à la répartition du PBG/tête (moyenne=1)
\end{tabular} & $\begin{array}{c}19,73 \% \\
0,6\end{array}$ & $\begin{array}{l}7,15 \% \\
\text { strielle » } \\
0.9\end{array}$ & $\begin{array}{r}8,33 \% \\
1,1\end{array}$ & $\begin{array}{r}3,67 \% \\
1,63\end{array}$ & $\begin{array}{r}2,70 \% \\
2,4\end{array}$ \\
\hline \begin{tabular}{|l} 
Encours de dette \\
- Par tête (1000 pesos) \\
(sept. 2001) \\
- Par rapport au PBG \% \\
- Sur revenu provincial. \\
\end{tabular} & $\begin{array}{c}55 \\
8,9 \\
261,7\end{array}$ & $\begin{array}{c}52 \\
7,8 \\
174,9\end{array}$ & $\begin{array}{c}29 \\
4,5 \\
85,3\end{array}$ & $\begin{array}{c}78 \\
15,6 \\
146,8\end{array}$ & $\begin{array}{c}99 \\
31,9 \\
185,7\end{array}$ \\
\hline
\end{tabular}

44 Porto (2004b, p.5), base 100 pour la Ville de Buenos Aires.

45 Cf. Porto (dir.), 2004, p.313.

Economie et Institutions $-\mathrm{n}^{\circ} 10$ et $11-1$ er $\& 2$ e semestre 2007 


\begin{tabular}{|c|c|c|c|c|c|}
\hline \begin{tabular}{|l|} 
Monnaie provinciale \\
Province
\end{tabular} & $\begin{array}{l}\text { Patacon } \\
\text { Buenos Aires }\end{array}$ & $\begin{array}{c}\text { Lecor } \\
\text { Cordoba }\end{array}$ & $\begin{array}{l}\text { No bonos } \\
\text { Santa Fé }\end{array}$ & $\begin{array}{c}\text { Federal } \\
\text { Entre Rios }\end{array}$ & $\begin{array}{c}\text { Cecacor } \\
\text { Corrientes }\end{array}$ \\
\hline $\begin{array}{l}\text { Dépenses de personnel } \\
\text { - par tête en } 2001 \\
\text { - emploi public / tête } \\
\text { - coût moyen de l'emploi } \\
\text { - \% dépense totale } \\
\text { Dépense en capital/total } \\
\end{array}$ & $\begin{array}{c}431 \\
30 \\
18 \\
52,3 \\
4,7 \% \\
\end{array}$ & $\begin{array}{c}447 \\
25 \\
18 \\
49,5 \\
6,7 \%\end{array}$ & $\begin{array}{c}468 \\
34 \\
14 \\
56,2 \\
5,1 \%\end{array}$ & $\begin{array}{c}585 \\
49 \\
12 \\
49,9 \\
9,2 \%\end{array}$ & $\begin{array}{c}478 \\
41 \\
12 \\
56,3 \\
11,7 \%\end{array}$ \\
\hline $\begin{array}{l}\text { Emissions monnaies provinciales (août 2002) } \\
\text { - en pesos courants } \\
\text { - \% revenus courants } \\
\text { - \% revenus propres } \\
\text { - Par tête } 2002 ; 2003 \\
\text { - \% PBG de } 2002 \\
\text { - \% dépenses province } \\
\text { - \% déficit de la Province }\end{array}$ & $\begin{array}{c}3411 \\
0,31 \\
0,54 \\
240 ; 211 \\
3,41 ; 2,75 \\
0,33 ; 0,27 \\
1,12 ; 3,14\end{array}$ & $\begin{array}{c}847 \\
0,29 \\
0,63 \\
229 ; 233 \\
2,9 ; 2,67 \\
0.28 ; 0,27 \\
1,77 ; 3,2\end{array}$ & $\begin{array}{l}\mathbf{0} \\
\mathbf{0} \\
\mathbf{0} \\
\mathbf{0} \\
\mathbf{0} \\
\mathbf{0} \\
\mathbf{0}\end{array}$ & $\begin{array}{c}388 \\
0,26 \\
0,77 \\
301 ; 254 \\
5,04: 3,75 \\
0,29 ; 0,23 \\
1,81 ; 2,10\end{array}$ & $\begin{array}{c}200 \\
0,37 \\
1,93 \\
216 ; 303 \\
4,88 ; 5.89 \\
0,30 ; 0,37 \\
-21,2:-13,4^{46}\end{array}$ \\
\hline $\begin{array}{l}\text { Monnaie provinciale (mars 2003) } \\
-\% \text { du circulant } \\
-\% \text { lecop } \\
-\% \text { total } \\
\end{array}$ & $\begin{array}{c}33 \\
5 \\
38 \\
\end{array}$ & $\begin{array}{c}30 \\
7 \\
37\end{array}$ & $\begin{array}{c}0 \\
17 \\
17\end{array}$ & $\begin{array}{c}47 \\
9 \\
56 \\
\end{array}$ & $\begin{array}{c}61 \\
8 \\
69 \\
\end{array}$ \\
\hline $\begin{array}{l}\text { Taux d'intérêt porté par les monnaies } \\
\text { fiscales }\end{array}$ & $7 \%$ & $7 \%$ & Sans objet & $4 \%$ & $4 \%-3 \%$ \\
\hline $\begin{array}{l}\text { Privatisation de la banque provinciale } \\
\text { Recettes de privatisation en \% revenu de la } \\
\text { Province } \\
1993-2001\end{array}$ & $\begin{array}{c}\text { Non } \\
\text { (grand réseau) } \\
\\
3,02\end{array}$ & $\begin{array}{c}\text { Interrompue } \\
\text { (grand réseau) } \\
0 \\
0\end{array}$ & 0,32 & $\begin{array}{c}\text { Oui } \\
\text { (réseau réduit) } \\
\\
2,56\end{array}$ & $\begin{array}{c}\text { Non } \\
0\end{array}$ \\
\hline Classification de Cetrangelo et alii, 2002. & $\begin{array}{c}\text { Important } \\
\text { déséquilibre } \\
\text { mais trajectoire } \\
\text { passée plus } \\
\text { ordonnée }\end{array}$ & $\begin{array}{l}\text { Important } \\
\text { déséquilibre } \\
\text { mais } \\
\text { trajectoire } \\
\text { passée plus } \\
\text { ordonnée } \\
\end{array}$ & \begin{tabular}{|c|} 
Politique \\
Fiscale \\
saine
\end{tabular} & $\begin{array}{c}\text { Déséquilibre } \\
\text { persistant et } \\
\text { incapacité à } \\
\text { assainir le } \\
\text { budget sur } \\
\text { 1995-2000 } \\
\end{array}$ & \begin{tabular}{|c} 
Haut niveau de \\
dette mais \\
déséquilibre \\
inférieur à la \\
moyenne \\
nationale
\end{tabular} \\
\hline
\end{tabular}

Pour ce qui concerne le poids de la dette publique, généralement considéré comme la clef de l'établissement de la confiance dans la monnaie (lorsque celle-ci est assimilée à la notion de crédibilité), le bilan est plus complexe à établir ${ }^{47}$. Tout d'abord il faut noter que l'ensemble des Provinces émettrices ont, quels que soient les indicateurs retenus, un niveau d'endettement élevé qui contraste avec le cas de Santa Fé, ce qui explique d'ailleurs sans

46 Le signe négatif correspond à un excédent budgétaire.

47 " (...) les variables explicatives de la valeur effective en pesos des bonos ont été les relations entre le niveau de l'émission et d'une part la base monétaire initiale, d'autre part les ressources fiscales propres des provinces, c'est-àdire les indicateurs les plus liés à la qualité transactionnelle qu'avaient ces monnaies. (...) Les indicateurs de la soutenabilité budgétaire, mesurée à travers les relations des revenus budgétaires totaux au déficit budgétaire d'une part, à la dette publique d'autre part, n'aident pas beaucoup à expliquer le phénomène de la différenciation des parités des diverses monnaies provinciales ..." (Argañaraz et alii, 2003, pp. 12 -13).

52 Economie et Institutions $-\mathrm{n}^{\circ} 10$ et $11-1$ er $\& 2$ e semestre 2007 
doute l'émission de monnaies provinciales ici et la non émission là, dans le contexte idéologique de la période. Ce contraste est sans doute corrélé avec celui relatif à l'importance des exportations hors Argentine dans l'économie provinciale, la province de Santa Fé exportant en 2000 près de deux fois plus de son PBG que les provinces de Buenos Aires et Cordoba, et près de six fois plus que les provinces d'Entre-Rios et Corrientes. Mais par delà cette commune différence vis-à-vis de la province de Santa Fé en matière d'exportations, les deux groupes de provinces émettrices se séparent aussi relativement à ce critère, ce qui peut participer à l'explication du différentiel de viabilité des émissions entre les deux groupes.

Cette différence se retrouve en matière d'endettement public, encore que son impact sur la viabilité des émissions provinciales soit plus difficile à établir dans la mesure où l'appréciation qu'on en fait dépend du type d'indicateur retenu. On peut en effet considérer que l'endettement des Provinces est aussi élevé, voire plus, dans le premier que dans le second groupe, si on le rapporte au revenu total des Provinces, Buenos Aires étant sous cet angle de loin la plus endettée de toutes. En revanche, rapporté au Produit Brut Géographique (PBG) et/ou au nombre d'habitants, c'est à l'opposé Corrientes qui est la plus endettée. Ainsi, alors que le ratio stock de dette / PBG n'est dans les provinces de Buenos Aires et Cordoba que deux fois plus élevé qu'à Santa Fé, il l'est de quatre fois dans l'Entre Rios, et de huit fois à Corrientes ${ }^{48}$. Enfin, il faut tenir compte ici de l'importance différenciée selon les provinces de la pré-affectation des fonds de la coparticipation au titre des garanties d'emprunts antérieurs, variable qu'il n'est pas facile de connaitre avec exactitude. Ces données, qu'on se propose d'élargir ultérieurement à d'autres provinces et de traiter plus systématiquement, confirment qu'il existe bien des conditions économiques structurelles limitatives des capacités provinciales à émettre de manière viable des fiat-monnaies, conditions qui touchent principalement à la taille de leurs économies et corrélativement à celle de leurs circuits du Trésor. Ces conditions peuvent être considérées comme relatives à l'établissement d'une confiance méthodique dans ces monnaies.

Néanmoins les Provinces en question ne sont pas des Etats séparés, mais font partie d'une même fédération et d'une même union monétaire. Elles ont affronté de fait une situation de crise qu'elles ont partagée avec l'Etat fédéral, lequel a lui aussi émis une monnaie fiscale non convertible au plan international à destination

48 On doit néanmoins noter que le niveau de l'endettement des provinces les plus pauvres de notre échantillon correspond à des dépenses en capital presque deux fois plus élevées que dans les provinces les plus riches.

Economie et Institutions - n 10 et $11-1$ er $\& 2$ e semestre 2007 
des Trésors provinciaux - la lecop -. Il en résulte que certaines des conditions économiques qui ont entraîné l'échec des monnaies provinciales en Entre Rios et à Corrientes, notamment celles qui touchent aux relations fisco-financières liant les Provinces à la Nacion et assurant ou non une redistribution de ressources entre des provinces de richesse fortement inégales, sont en fait de nature éminemment politique. Dit autrement, ces échecs peuvent être imputés à un défaut de solidarité fisco-financière entre provinces riches et pauvres au sein de la fédération. Cette solidarité est en effet une variable centrale pour les provinces de tailles économique et démographique faibles, obligatoirement plus dépendantes de leur environnement extérieur que les plus grandes provinces.

En outre, comme on l'a vu ci-dessus dans le cas de l'Entre Rios, les conditions politiques internes aux provinces sont également des variables clefs pour l'établissement de la confiance hiérarchique et éthique dans une monnaie régionale, ne serait-ce que parce qu'elles conditionnent immédiatement l'économie du monnayage provincial et donc la régulation quantitative de l'émission des bonos.

\subsection{Préconditions politiques et symboliques}

L'expérience des monnaies provinciales s'est déroulée dans le cadre d'une crise économique et politique sans précédent à l'échelle de la Nacion, contexte général qui explique non pas leur apparition, mais leur généralisation, $\mathrm{y}$-compris dans des situations régionales où elles étaient improbables et a priori peu viables, cas notamment de l'Entre Rios (du fait, nous l'avons vu, d'une part de l'histoire de la province, d'autre part de la conjoncture politique qui y régnait). Plus généralement le contexte politique du currency board et de sa crise, s'il explique la multiplication des monnaies régionales, n'apparaît pas en revanche particulièrement favorable à leur viabilité, vu l'état de défiance généralisé de la population à l'égard de ses représentants et dirigeants politiques. Les conditions économiques ont également créé le besoin de leur résurgence, mais dans les provinces les plus défavorisées du pays, elles n'ont pas été non plus favorables à l'établissement et au maintien de la confiance en leur valeur nominale. L'Etat fédéral cherchant avec plus ou moins de succès à transférer ses contraintes budgétaires et fiscales sur les Provinces, il régnait une concurrence très conflictuelle entre les deux ordres de gouvernement qui explique que les conditions politiques internes aux provinces aient été la variable clef dans le succès ou l'échec des expériences. Or la viabilité d'un système de monnaies provinciales présuppose au contraire une coopération à l'échelle de la fédération,

54 Economie et Institutions - n 10 et $11-1$ er \& 2e semestre 2007 
basée sur une complémentarité des monnaies régionales avec la (ou les) monnaie(s) nationale(s) ${ }^{49}$.

Le résultat des élections législatives de 2001 où le grand gagnant est le vote blanc ou annulé témoigne du manque grave de légitimité des élites et partis politiques (Vilas, 2001), lequel atteindra son apogée avec le "Que se vayan todos!" de 2002. Les capacités de négociation des gouvernements provinciaux avec le gouvernement national ont été marquées par ce phénomène et la différenciation de son intensité selon les provinces. La Province de Buenos Aires a bénéficié d'une relation privilégiée en raison de la nécessité pour le gouvernement fédéral de pouvoir compter avec son appui législatif aux autres mesures draconiennes qu'il voulait prendre : déficit zéro, réduction des salaires, etc. C'est ce qui permit au patacón d'être accepté pour le paiement des impôts nationaux, privilège exclusif auquel n'eurent pas accès les autres provinces. Celles-ci furent obligées de mettre en place des caisses de conversion comme dans le cas de l'Entre Rios et de Cordoba. La situation politique eut dans l'Entre Rios une grande importance, le gouvernement étant en permanence confronté à des protestations sociales entraînées par les licenciements, les retards de paiement des salaires et des pensions, une mauvaise assignation des dépenses publiques, etc. L'appartenance du gouverneur entrerriano au même parti politique que celui du Président de la République, Fernando De la Rua, on l'a $\mathrm{vu}$, ne régla rien. L'opposition péroniste provinciale put au contraire exploiter les contradictions internes de l'Alliance (entre le Parti Radical et le FREPASO) soutenant le Président de la république, lesquelles avaient déjà conduit à donner à Domingo Cavallo, le père du currency board, des pouvoirs extraordinaires. Cela se traduisit par des poursuites en justice du Gouverneur, le refus de soutenir franchement le lancement de la nouvelle monnaie ainsi que les nouvelles émissions. Sur cette toile de fond de lutte politique, le

49 Une certaine coopération a néanmoins existé dans la crise mais est restée tacite. En effet, alors que les émissions de monnaies provinciales (bonos) ont été soutenues juridiquement par les Cours suprêmes de justice provinciales invoquant la force majeure d'un état de nécessité et urgence, la Cour Suprême de justice fédérale n'a jamais été appelé à statuer sur leur légalité. Cela signifie qu'il existait un soutien fédéral tacite à leur émission, laquelle à l'origine fut d'ailleurs aussi soutenus, voire incitée par le ministre fédéral de l'Economie de l'époque, Domingo Cavallo,. Tout s'est donc passé comme si les gardiens de l'orthodoxie, pour sauver la convertibilité, cherchaient une voie de sortie hétérodoxe dans un pluralisme monétaire - dualité de la monnaie nationale et "terceras monedas" dans les provinces, permettant de contourner une contrainte budgétaire dure devenue intenable au plan économique et social. Par ailleurs au plan fiscal, au moins jusqu'en 1999 comme le montre Bonvecchi (2005), le conflit fédéral/fédéré trouvait des solutions de compromis à court terme en faisant l'objet d'une négociation quasi-permanente qui stabilisait le rapport de forces.

Economie et Institutions $-\mathrm{n}^{\circ} 10$ et $11-1$ er $\& 2$ e semestre 2007 
federal n'a joué un rôle unificateur qui n'a été que relatif et momentané. Ce qui ne fut pas le cas dans la province de Buenos Aires où le Parlement provincial soutint l'émission des diverses séries de patacones. De même, dans la province de Córdoba, l'opposition "allianciste" minoritaire appuya les émissions de lecor.

Les variables politiques sont également cruciales pour comprendre l'échec du cecacor dans la province de Corrientes. Mais dans ce cas, il s'agit de variables spécifiques, différentes de celles qui expliquent l'échec dans l'Entre Rios. En effet, la monnaie provinciale a été institué à Corrientes dès décembre 1999 par un interventor, c'est-à-dire par un Gouverneur non pas élu, mais nommé par le gouvernement fédéral pour sortir la Province d'une crise politique et financière grave (avec destitution du Gouverneur en place, arrestation pour corruption du Maire de la capitale - ancien Gouverneur de 1994 à 1997, endettement disproportionné par rapport aux ressources, détournement de fonds publics, non paiement des salaires des fonctionnaires et des retraites, émeutes urbaines) ${ }^{50}$. Comme on l'a déjà signalé, c'est l'ancien Gouverneur radical de Cordoba, Ramon Mestre, et son équipe cordobés, auréolés du prestige associé au succès de l'expérience du cecor créé en 1995 dans cette province ${ }^{51}$, qui ont cherché à répliquer l'expérience en créant le cecacor fin 1999. Mais ce dernier ne connaitra pas le même succès, étant donné les situations économiques et politiques très différentes des deux provinces, mais aussi le changement général de conjoncture ${ }^{52}$.

En bref, l'élargissement de l'analyse aux autres provinces ayant fait les émissions de bonos les plus importantes confirme les résultats de la comparaison des expériences du patacon et du federal. Il montre le caractère primordial des dimensions politiques et symboliques de l'établissement de la confiance dans ces monnaies. Sous cet angle encore, comme le montre le tableau 5 qui regroupe divers indicateurs qualitatifs de ces dimensions, la province de Cordoba est proche de celle de Buenos Aires, tandis que celle de Corrientes rappelle celle de l'Entre-Rios. La légitimité des Gouverneurs et des institutions politiques combinée à une relative faiblesse de la conflictualité politique et sociale apparaissent ici

50 La province avait déjà été mise sous intervention fédérale en 1992 et 1993. Sur cette crise à Corrientes, cf. Perez-Sosto, 2006.

51 Non seulement le cecor n'avait pas subi de dévaluation, mais il avait permis à la Province de revenir à l'équilibre budgétaire l'année suivante.

52 Entrevue avec Oscar Aguad, Interventor fédéral pour la municipalité de Corrientes en décembre1999, puis pour la Province, de mars à décembre 2001 (Buenos Aires, 1er mars 2006). En fait, seule la première série de cecacor émise circula sans dévaluation, comme pour le federal, et l'intervention permit de réduire la dette publique de la Province et des Municipalités en dégageant un excédent budgétaire.

56 Economie et Institutions - n 10 et $11-1$ er \& 2e semestre 2007 
comme des conditions du succès. Pourtant, les Provinces de Cordoba et de Corrientes sont dans des relations avec le gouvernement fédéral qui diffèrent significativement de celles valant respectivement pour les Provinces de Buenos Aires et de l'Entre-Rios.

Ainsi malgré l'importance de Cordoba dans l'économie générale du pays, la lecor n'a pas bénéficié du privilège fiscal concédé au patacon, et a du s'appuyer comme l'Entre Rios sur une caisse de conversion. A l'opposé, Corrientes était sous la tutelle du gouvernement fédéral quand fut lancé le cecacor, ce qui constitue une différence politique importante avec le cas de l'Entre Rios. D'où la nécessité de relativiser l'influence de la variable "relations Nacion/Provinces " sur la viabilité des monnaies provinciales, et, en conséquence, de donner une place prépondérante aux variables politiques et symboliques internes à chaque province.

Ces différences de contextes politiques dans les quatre provinces sous revue se reflètent dans la variété des degrés d'intensité des négociations entre gouvernements et secteurs privés destinées à assurer la circulation des monnaies créées. Ainsi, tandis que le patacón, comme la lecor à un degré moindre vu le caractère strictement provincial de sa circulation, a été d'emblée accepté dans presque toutes les transactions, le federal et le cecacor (à un degré encore plus élevé) n'ont pas connu le même sort, une grande partie des commerces ne l'ayant accepté que sous la contrainte et au prix d'une décôte de plus en plus importante. Pour autant, le caractère strictement provincial de ces deux dernières monnaies - lié au fait qu'elles n'avaient pas de pouvoir libératoire des dettes fiscales nationales - conjugué à l'étroitesse économique de l'espace provincial de leur circulation, n'explique pas totalement leur échec, ce que montre a contrario le cas de la lecor cordobesa. Il faut y ajouter d'une part l'importance quantitative des émissions qui, quant à elle, est une variable politique locale, d'autre part les degrés de stabilité et de crédibilité des pouvoirs politiques locaux.

En effet dans les deux cas de l'Entre Rios et de Corrientes, les premières émissions n'ont pas été suivies de dévaluations, mais n'ont pas non plus été appropriées par le marché local (absence de véritable confiance méthodique), ni entraîné de dynamisation de l'économie provinciale (absence d'effets multiplicateurs), alors que ce fut au contraire le cas dans les provinces de Buenos Aires et de Cordoba. Dans 1'Entre-Rios, qui a une économie de taille non négligeable, il faut mettre cet échec au compte du mauvais climat politique régnant dans la province et d'une politique vis-à-vis des commerces insuffisamment active. Dans le cas de Corrientes, province dont l'économie et les ressources fiscales propres sont très faibles et peu dynamiques, le climat politique et la crise constitutionnelle des institutions provinciales ont certes joué le même type de rôle délétère, mais s'y ajoute aussi l'incapacité 
paradoxale des interventores fédéraux à donner au cecacor un statut fédéral identique à celui du patacon. En effet, le cecacor, s'il avait été admis en paiement des dettes fiscales fédérales, aurait alors été parfaitement viable sans préjudice pour la Nacion, dans la mesure où la forte dépendance de la Province vis-à-vis des ressources fédérales aurait assuré le retour du bono dans sa province d'origine et, par là même, la confiance dans sa valeur nominale. Certes la plus grande partie des transferts de coparticipation devant échouer à Corrientes servait en fait au paiement des dettes accumulées par les précédents gouvernements provincial et municipaux, mais la coparticipacion ne représentait qu'un peu plus de la moitié du total des transferts fédéraux à la Province (Piffano, 2004, p. 22). On voit donc ici l'incohérence d'une politique fédérale d'intervention qui institue une monnaie de secours sans se soucier d'établir les conditions de la confiance qui doit assurer sa circulation au pair ; le cecacor est ainsi apparu comme une monnaie allogène paradoxalement non soutenue par la puissance tutélaire extérieure qui l'instituait ${ }^{53}$.

53 Le caractère allogène du cecacor ressort bien des critiques parlementaires et des poursuites judiciaires entamées pour excès de pouvoir contre les interventores fédéraux à partir de 2003-2004, après le retour à un gouvernement provincial élu. Quant à l'absence de soutien fédéral, il conduit à se demander si le but de l'intervention fédérale n'était pas purement et simplement de dévaloriser les dettes de la Province pour y restaurer la paix sociale.

58 Economie et Institutions - n 10 et $11-1$ er \& 2e semestre 2007 
Tableau 5 : Conditions politiques et symboliques de viabilité

\begin{tabular}{|c|c|c|c|c|}
\hline Viabilité de la monnaie & $\begin{array}{c}\text { Patacon } \\
\text { Buenos Aires }\end{array}$ & $\begin{array}{c}\text { Lecor } \\
\text { Cordoba }\end{array}$ & $\begin{array}{c}\text { Federal } \\
\text { Entre-Rios }\end{array}$ & $\begin{array}{c}\text { Cecacor } \\
\text { Corrientes }\end{array}$ \\
\hline $\begin{array}{l}\text { Couleur politique: } \\
\text { - Gouverneur- Parlement }\end{array}$ & $\begin{array}{l}\text { Péroniste } \\
\text { Majorité } \\
\text { Radicale }\end{array}$ & $\begin{array}{l}\text { Péroniste } \\
\text { Pas de } \\
\text { majorité }\end{array}$ & $\begin{array}{l}\text { Radical } \\
\text { Majorité } \\
\text { péroniste }\end{array}$ & $\begin{array}{l}\text { Interventor fédéral } \\
\text { (Radical) } \\
\text { hors circuit }\end{array}$ \\
\hline $\begin{array}{l}\text { Niveau de légitimité } \\
\text {-.Gouverneur } \\
\text { - Gouvernement } \\
\text { - Emissions }\end{array}$ & $\begin{array}{l}\text { moyen } \\
\text { fort } \\
\text { fort }\end{array}$ & $\begin{array}{l}\text { fort } \\
\text { fort } \\
\text { bon }\end{array}$ & $\begin{array}{c}\text { très faible } \\
\text { faible } \\
\text { moyen puis faible }\end{array}$ & $\begin{array}{l}\text { nul puis bon } \\
\text { bon } \\
\text { fort puis de }+ \text { en }+ \\
\text { faible }\end{array}$ \\
\hline $\begin{array}{l}\text { Degré de conflictualité } \\
\text { politique interne } \\
\text { - au niveau provincial avec } \\
\text { opposition } \\
\text { - provincial/ municipal } \\
\end{array}$ & $\begin{array}{l}\text { Faible } \\
\text { absente }\end{array}$ & $\begin{array}{l}\text { Faible } \\
\text { absente }\end{array}$ & Très fort & $\begin{array}{l}\text { Fort } \\
\text { Faible } \\
\end{array}$ \\
\hline $\begin{array}{l}\text { Degré de conflictualité sociale } \\
\text { - fonction publique } \\
\text { - autres secteurs }\end{array}$ & $\begin{array}{l}\text { Faible, } \\
\text { médiation } \\
\text { juridique } \\
\text { Faible }\end{array}$ & $\begin{array}{l}\text { Faible } \\
\text { Faible }\end{array}$ & $\begin{array}{c}\text { Très fort } \\
\text { Fort }\end{array}$ & $\begin{array}{l}\text { Fort } \\
\text { Fort }\end{array}$ \\
\hline $\begin{array}{l}\text { Rapport de force } \\
\text { provincial/fédéral } \\
\text { - Capacité de négociation } \\
\text { - Appui fédéral à la monnaie } \\
\text { provinciale }\end{array}$ & $\begin{array}{c}\text { Très bon } \\
\text { Très bonne } \\
\text { Fort }\end{array}$ & $\begin{array}{l}\text { Bon } \\
\text { Faible } \\
\text { Moyen }\end{array}$ & $\begin{array}{l}\text { Mauvais } \\
\text { Faible } \\
\text { Faible }\end{array}$ & $\begin{array}{c}\text { Nul } \\
\text { Très faible } \\
\text { Ambivalent }\end{array}$ \\
\hline $\begin{array}{l}\text { Stratégie pour } \\
\text { assurer l'acceptation } \\
\text { marchande du bono } \\
\end{array}$ & Systématique & Active & Non systématique & Peu active \\
\hline $\begin{array}{l}\text { Type de confiance } \\
\text { hiérarchique recherchée }\end{array}$ & $\begin{array}{l}\text { Assurée par } \\
\text { coordination } \\
\text { fiscale avec le } \\
\text { fédéral }\end{array}$ & $\begin{array}{l}\text { Non assurée } \\
\text { par le fédéral } \\
\text { mais à défaut } \\
\text { par Caisse de } \\
\text { conversion }\end{array}$ & $\begin{array}{l}\text { Non assurée } \\
\text { par le fédéral } \\
\text { mais à défaut par } \\
\text { Caisse de } \\
\text { conversion }\end{array}$ & $\begin{array}{l}\text { Autorité du } \\
\text { gouvernement } \\
\text { fédéral sur la } \\
\text { Province }\end{array}$ \\
\hline $\begin{array}{l}\text { Acceptation du bono hors de } \\
\text { la province } \\
\text { - paiement des impôts } \\
\text { fédéraux } \\
\text { - circulation marchande }\end{array}$ & $\begin{array}{l}\text { Oui } \\
\text { Oui } \\
\text { Oui }\end{array}$ & $\begin{array}{l}\text { Non } \\
\text { Non } \\
\text { Oui }\end{array}$ & $\begin{array}{l}\text { Non } \\
\text { Non } \\
\text { Non }\end{array}$ & $\begin{array}{l}\text { Non } \\
\text { Non } \\
\text { Non }\end{array}$ \\
\hline $\begin{array}{l}\text { Anciennes expériences de } \\
\text { papier monnaie local } \\
\text { - accoutumance } \\
\text { - succès (objectif et subjectif) }\end{array}$ & $\begin{array}{l}\text { Oui } \\
\text { Oui (ancien) } \\
\text { ambivalent }\end{array}$ & $\begin{array}{l}\text { Oui } \\
\text { Oui (récent) } \\
\text { oui } \\
\end{array}$ & $\begin{array}{l}\text { Non } \\
\text { Non : refus }\end{array}$ & $\begin{array}{c}\text { Oui } \\
\text { Oui (ancien) } \\
\text { non } \\
\end{array}$ \\
\hline $\begin{array}{l}\text { Référence aux valeurs } \\
\text { fondatrices de la province et } \\
\text { de son autonomie/fédération }\end{array}$ & $\begin{array}{c}\text { Forte, unitariste } \\
\text { et avec effets } \\
\text { favorables à } \\
\text { l'émission } \\
\text { Le Patacon est } \\
\text { une monnaie } \\
\text { quasi nationale }\end{array}$ & $\begin{array}{l}\text { Forte, } \\
\text { fédéraliste, } \\
\text { avec effets } \\
\text { favorables à } \\
\text { l'émission } \\
\text { Autonomie } \\
\text { provinciale }\end{array}$ & $\begin{array}{l}\text { Forte, unitariste, } \\
\text { mais avec effets } \\
\text { défavorables à } \\
\text { l'émission } \\
\text { Urquiza, père de } \\
\text { l'unification } \\
\text { monétaire } \\
\text { argentine }\end{array}$ & $\begin{array}{l}\text { Forte, fédéraliste, } \\
\text { avec effets } \\
\text { défavorables à } \\
\text { l'émission d'une } \\
\text { monnaie importée- } \\
\text { instituée par des } \\
\text { cordobenses avec } \\
\text { l'appui du Fédéral }\end{array}$ \\
\hline $\begin{array}{l}\text { Assimilation possible à une } \\
\text { monnaie communautaire }\end{array}$ & $\begin{array}{c}\text { Forte } \\
\text { appropriation } \\
\text { par la } \\
\text { population }\end{array}$ & \begin{tabular}{|c|} 
Forte \\
appropriation \\
par la \\
population
\end{tabular} & $\begin{array}{l}\text { Très faible } \\
\text { appropriation par } \\
\text { la population }\end{array}$ & $\begin{array}{c}\text { Faible appropriation } \\
\text { par la population }\end{array}$ \\
\hline
\end{tabular}

Economie et Institutions $-\mathrm{n}^{\circ} 10$ et $11-1$ er $\& 2$ e semestre 2007 
Il faut noter également que dès lors que la convertibilité fut abandonnée et le peso dévalué, et que les monnaies provinciales se mirent à représenter une part très importante de la masse monétaire nationale, l'importance de ces variables politiques internes comme condition de la viabilité différentielle des monnaies selon les provinces s'est considérablement accrue.

Enfin, une dernière variable d'importance est celle relative aux différences marquées en matière de traditions d'utilisation de telles monnaies. Même en se bornant à l'histoire récente, le Nord-Est argentin avait une expérience de presque 20 ans en la matière, ce qui y rendait a priori plus facile l'acceptation d'une monnaie provinciale dès lors qu'elle s'appuyait sur l'existence d'un circuit monétaire empêchant les favoritismes et les manœuvres spéculatives qui avaient pu grever les expériences antérieures (cas de Catamarca, La Rioja, Tucuman). Le cas de Córdoba où la lecor pouvait profiter de l'apprentissage donné par l'expérience récente réussie du cecor, attire aussi l'attention sur l'importance des évaluations retenues par les populations des expériences antérieures.

\section{Conclusion}

Les monnaies fiscales provinciales argentines dont on vient de retracer une partie de l'histoire ont disparu du paysage argentin fin 2003. Avec l'abandon du currency board et la fin de la convertibilité au pair du peso avec le dollar, et après une période de stabilisation du système monétaire, elles ont été, moyennant un montage financier dont la description dépasse le cadre de cet article, " rachetées " par l'Etat fédéral et changées en pesos émis par la Banque centrale à un prix (taux de change) se rapprochant de leur valeur de marché. Après les cinq années de forte croissance et de relative stabilisation politique qu'a connu l'Argentine depuis sa crise, discuter de la viabilité de telles monnaies peut paraître dépassé, voire même oiseux, même si, sur le fond, comme le montre la situation très conflictuelle actuelle, les problèmes fisco-financiers de la fédération argentine qui ont été à l'origine de leur généralisation n'ont pas été réglés. La nécessité d'avancer vers un nouveau système de transferts Nacion-Provinces apparaît encore en effet sur les agendas de la plupart des organisations politiques qui, en général, critiquent la part dirimante qu'ont pris les transferts discrétionnaires dans l'ensemble des transferts fédéraux, mais n'entrent guère dans une discussion de fond sur les changements institutionnels politique, budgétaire et monétaire - qu'implique une réforme du système des transferts fédéraux-provinciaux dans une fédération.

En effet, comme on vient de le voir, le système des transferts intergouvernementaux et les valeurs socio-politiques qui le conforment et le légitiment sont au cœur des confiances méthodique, hiérarchique et éthique qui sont nécessaires pour stabiliser le régime

60 Economie et Institutions - n²10 et $11-1$ er $\& 2$ e semestre 2007 
monétaire. L'Argentine montre aussi que, réciproquement, on ne peut fonder une fédération sur un régime fédéral de péréquation fisco-financière entre entités fédérées (le régime économique de la fédération) avec n’importe quel régime monétaire. Ainsi le régime argentin de la convertibilité (currency board), en déstabilisant le régime fiscal de la coparticipacion, s'est-il vu en retour annihilé par les effets de cette déstabilisation, la menace sur l'unité de la communauté monétaire nationale relevant moins des prises d'autonomie monétaire de certains gouvernements provinciaux que du régime de la convertibilité qui les a suscitées. Ce régime a en effet conduit à une forte centralisation politique de la fédération qui a exacerbé les tensions entre Nacion et Provinces (dévolution des dépenses et restrictions dans la redistribution des ressources fiscales) ainsi qu'entre Provinces, en raison des inégalités qui les séparent face aux restrictions de leurs ressources et l'accroissement de leurs charges administratives.

L'émergence des monnaies provinciales n'a fait alors que montrer le caractère non soutenable, non viable d'un régime monétaire qui dénie à tous les niveaux de la puissance publique le droit d'émettre des moyens de paiement pour alimenter leur circuit fiscal et les soumet à un régime d'émission réglé par la seule logique de l'accumulation de capital économique ${ }^{54}$.

Ainsi est-on conduit à penser que ce n'est pas tant la pluralité des monnaies fiscales qui pose problème à la communauté monétaire argentine que l'inadaptation du mode standard de régulation de cette pluralité qui conduit à interdire toute émission publique décentralisée de monnaie sans tenir compte de ses fondements logiques dans ce qui fait la spécificité du politique dans une fédération par rapport à un Etat unitaire. Aussi la solution à ce qui est le plus souvent vu comme le type même de l'anarchie monétaire, la prolifération de monnaies fiscales émises par des entités fédérées, ne devrait pas être conçue a priori, selon un préjugé centraliste, dans les termes de leur élimination, c'est-à-dire par la simple réaffirmation du monopole monétaire de l'Etat fédéral confondu avec un Etat central. Elle devrait aussi être envisagée en termes de réglage des émissions - comme dans le cas des réseaux bancaires - dans le cadre d'un régime fédéral de monnayage organisant la complémentaritésolidarité de ces monnaies via des mécanismes de compensation permettant de tenir les parités. Dans cette perspective, le régime fédéral de péréquation (coparticipacion) fiscale jouerait pour les

54 Lorsque la seule règle jugée convenable est "émission zéro " " déficit cero "), on ne peut envisager l'institution de règles de monnayage qui, tout en unifiant le système monétaire à l'échelle de la fédération, pourraient soutenir au niveau provincial des dynamiques fisco-financières plus favorables au développement économique local et à la réduction des inégalités de richesse entre provinces.

Economie et Institutions $-\mathrm{n}^{\circ} 10$ et $11-1$ er $\& 2$ e semestre 2007 
monnaies fiscales un rôle équivalent à celui du prêteur en dernier ressort pour les monnaies bancaires.

Dès lors qu'on est prêt à reconnaître à la puissance publique le droit de battre monnaie et qu'on ne considère pas que ce droit conduit inéluctablement à l'instabilité monétaire (ce qui devrait conduire sinon à proposer une privatisation intégrale de la banque centrale), alors il convient de tenir compte de ce que dans une fédération, la répartition des compétences entre les ordres fédéral et fédéré de gouvernement, chacun d'eux étant souverain dans ses domaines de compétence, fait qu'il n'y a pas unité a priori du circuit fiscal, les circuits fiscaux provinciaux étant partiellement autonomes et fermés sur eux-mêmes. Il en découle que des émissions mesurées de monnaies provinciales (en rapport notamment avec la taille des circuits provinciaux du trésor, l'ampleur et la régularité des transferts fiscaux fédéraux-provinciaux, le degré d'ouverture et de dépendance extérieure des économies régionales), d'une part sont nécessaires pour que les gouvernements provinciaux soient en état d'exercer leurs compétences souveraines et de stimuler le développement local, d'autre part sont parfaitement viables au sens où elles ne menacent pas la stabilité monétaire.

Plus précisément, un accord fisco-monétaire sur le paiement de tous les impôts nationaux comme provinciaux et municipaux par des monnaies fiscales provinciales et fédérale est nécessaire pour articuler les circuits provinciaux avec le circuit fédéral de manière à fonder une confiance méthodique dans l'ensemble de ces instruments de paiement. En effet, ce qui vaut pour les monnaies marchandes des différents réseaux bancaires privés, vaut tout autant pour les divers circuits provinciaux du Trésor public. Un tel accord passé sous forme de loi fonderait une confiance hiérarchique dans le système, dès lors que cette loi comprendrait la mise en place d'une caisse de compensation interprovinciale qui interviendrait comme organe régulateur des émissions provinciales et où la Banque centrale serait représentée. La confiance éthique dans ces monnaies pourrait enfin trouver ses fondements dans le compromis politique qu'institue un tel système entre les problématiques communautaires provinciales et l'appartenance à la Nacion.

Comme le suggérait Julio Olivera (1992) dans son analyse de l'inadéquation de la Banque centrale argentine à la structure politique fédérale du pays, et comme nous l'avons montré dans la troisième partie de cet article, il existe manifestement des conditions précises - politiques, économiques et symboliques - pour que des émissions de monnaies provinciales favorables au développement local et à la réduction des inégalités interprovinciales, soient soutenables dans la durée et ne créent pas d'instabilité monétaire. Mais ces conditions ne se réduisent pas à l'interdiction généralisée de telles émissions. Au plan juridique, la légalité des émissions de

62 Economie et Institutions - n 10 et $11-1$ er \& 2e semestre 2007 
monnaies par les Provinces ne fait en Argentine pas de doute dès lors que celles-ci sont autorisées par le Congrès Fédéral. Ainsi si une nouvelle loi régissant la coparticipación incluait un chapitre monétaire, cela donnerait un fort appui symbolique aux monnaies provinciales. Mais un telle considération devrait s'inscrire dans une discussion plus large concernant la stratégie de développement. Pourrait s'y inscrire également, comme le suggère le succès de la lecop ayant circulé dans le circuit fédéral du Trésor, une discussion sur le relachement de la contrainte de convertibilité externe de la monnaie nationale par différenciation des instruments monétaires de réserve et de circulation, différenciation qui recoupe celle qui sépare les deux sphères des échanges respectivement extérieurs et intérieurs.

\section{BIBLIOGRAPHIE}

Aglietta, M. et A. Orléan (dir.) (1998), La monnaie souveraine, Paris, Odile Jacob.

Alberdi, J. B. (1996) "Escritos póstumos de J.B. Alberdi. Estudios Económicos" Tomo I, Universidad Nacional de Quilmes (original de 1895).

Argañaraz, N., Capello, M. et J. Garzon (2003), "Cuasi-monedas provinciales : un análisis de su existencia y actual rescate ", IERAL, Fundación Mediterranea, Documentos de trabajo, Serie Política fiscal, junio.

Banco Mundial (2001), Argentina, Finanzas Provinciales, Actualización IV, Informe final.

Bonvecchi, A. (2005), "Les aspects politiques du fédéralisme budgétaire argentin à l'aune des négociations fiscales fédérales ", Problèmes d'Amérique latine, 56, pp. 129-152.

Boyer-Xambeu, M.-T., Deleplace, G. et L. Gillard (1986), Monnaie privée et pouvoir des princes, Paris, FNSP - CNRS.

Capello, M. (1995), "Analisis Economico de la Ley de Emergencia Provincial ", Actualidad Económica, Ano V, n 27, pp. 3-7.

Capon Filas, JP (2003), "Análisis constitucional de las cuasimonedas provinciales ", La Ley, Buenos Aires, 7 de mayo.

Cepeda, 0. (2006), El federal Entrerriano : Documentos sobre bonos provinciales de Gabriel Obradovitch, Nogoya, courriel aux auteur du 14 février.

Cetràngolo, 0. et F. Gatto (2002), Las provincias en la crisis argentina. Algunos elementos para discutir las prioridades de la cooperacion internacional, documento pour le séminaire "Argentina un anno dopo : quale cooperazione ?", CESPI et IILA, Rome, 6 décembre.

Cetrangolo, 0., Jimenez, J. P., Devoto F. y D. Vega, (2002), "Las finanzas publicas provinciales: situación actual y perspectivas ", 
CEPAL, Buenos Aires, Serie Estudios y Perspectivas, $n^{\circ} 12$, diciembre.

Chelala, S. (2003), "La utilización de terceras monedas. El caso argentino ", 9 avril, www.nodo50.org/cubasigloXXI/congreso/chelala_10abr03.pdf

Clarke, G. R.G. et R. Cull (1999), "Why Privatize ? The Case of Argentina's Public Provincial Banks ", World Development, 27(5), pp. 865-886.

Colliac, S. (2004), Fiscal Federalism, Dollarization of Public Contracts and the Exchange Rate Regime, draft, 14 septembre.

Damill, M., Frenkel, R. y L Juvenal (2004), "Las cuentas públicas y la crisis de la convertibilidad en Argentina ", in Boyer, R y J. C. Neffa (coord.), La economía argentina y su crisis (1976-2001), Buenos Aires, CEIL-PIETTE et Miño y Dávila, pp. 291-321..

Dirección Provincial de Estadística (2004), Encuesta de ventas minoristas, 2001 -2003, Informe anual, Noviembre.

Dirección Nacional de Coordinación Fiscal con las Provincias, Grupo Deuda (2004), Cuasimonedas, mimeo.

Dufy, C. et F. Weber (2006), Ethnographie économique, Paris, La Découverte, Repères.

Eggers, F. (2001), El Patacon. Surgimiento, evolución y ocaso, Présentation powerpoint par le Director provincial de politica de financiamiento y credito publico, Provincia de Buenos Aires.

Fahler Lopez, G. (2001), "Patacon : mueve la economía pero no descomprime a Ruckauf. El efecto reactivante de una moneda secundaria que solo alivia el gran déficit de Buenos Aires ", Ambito Financiero, 29 août, p.5.

Fuchs, M. (2004), "La insercion externa de las provincias argentinas. Rasgos centrales y tendencias a comienzos de 2000 ", Estudios y perspectivas, $\mathrm{n}^{\circ} 20$, CEPAL.

Hintze, S. (ed.) (2003), Trueque y Economia Solidaria, Buenos Aires, Prometeo Libros y Universidad Nacional de General Sarmiento.

Ingham, G. (2004), The nature of money, Cambridge (UK), Polity Press.

Irigoin, M. A. (2000), "Inconvertible Paper Money, Inflation and Economic Performance in Early Nineteenth Century Argentina.", Journal of Latin American Studies, $\mathrm{n}^{\circ} 32$, pp. 333-359.

Journaux : Ambito Financiero, Clarin, La Nacion, El dia (La Plata), El Diario (Paraná), (2001-2004), multiples numéros

Lafferrière, L. (2004), El desfinanciamiento del sector público en la provincia Entre Rios. Su reflejo en la emisión de cuasimonedas, Seminario de Economías Regionales, Tercer Encuentro de Universidades Nacionales en el Marco del Plan Fénix.

Le Maux, L. (2001). "Le prêt en dernier ressort. Les chambres de compensation aux Etats-Unis durant le XIX ${ }^{\circ}$ siècle ". Annales HSS, 6, pp. 1223-1251.

64 Economie et Institutions - n²10 et $11-1$ er \& 2e semestre 2007 
Licari, J. M., Calgagno J. C., Oviedo, J. M. y Pellegrini S. (sans date), "Cuasimonedas provinciales. Medición absoluta y comparada ", 'Observatorio de la Economia, Universidad Nacional de Córdoba.

Luzzi, M. (2005), Réinventer le marché. Les clubs de troc face à la crise en Argentine, Paris, L'Harmattan.

Obradovich, G. (2004), " La desvalorización de los bonos provinciales como perdida de las capacidades estatales. El caso del federal en Entre-Rios ", Ponencia al Segundo Congreso Nacional de Sociología y VI Jornadas de Sociologia de la UBA, Buenos Aires, 20-23 de octubre.

Olivera, J. (1981), "Economía regional, política monetaria y desarrollo económico ", Informe Económico, CIEC, marzo, pp. 15-17.

Olivera, J. (1989), "Descentralización geogràfica de la banca central", in Finanzas Pùblicas y Desarrollo Regional. Ensayos en Honor de Horacio Nuñez Miñana, L.E. Di Marco (coord.), Côrdoba, pp. 333-342. Olivera, J. (1992), "Banca central, federalismo económico y constitución monetaria", Nuevas Propuestas. Revista de la Universidad Católica de Santiago del Estero, junio, pp. 7-17.

Orléan, A. (2007), "L’hyperinflation allemande des années 1920 ", in B. Théret (dir.), La monnaie dévoilée par ses crises, Paris, Editions de l'EHESS, Vol. 2, pp. 187-220.

Ould-Ahmed, P. (2008), "Les formes du politique dans les "clubs de troc" en Argentine", Working Paper Recherche et Régulation n²0081 , série MF.

Perez-Sosto, G. (2006), Análisis de los factores intervinientes en la crisis de estado en la provincia de Corrientes. Relaciones entre Sociedad Civil y clase politica en un contexto de crisis : un análisis cualitativo desde el discurso de los actores sociales, (con la colaboracion de M. Romero), Informe preliminar.

Pifano, H. (2004), "Los sistemas tributarios federales y la evolución del federalismo fiscal en Argentina ", Nota 2, PrEBi, Universidad Nacional de la Plata.

Porto, A. (2004), "Finanzas Publicas subnacionales : La Experiencia Argentina ", Documento de Federalismo Fiscal, $\mathrm{n}^{\circ} 12$, Universidad Nacional de la Plata, septiembre.

Porto, A. (dir.) (2004), Disparidades Regionales y Federalismo Fiscal, Universidad Nacional de la Plata, mars.

Saiag, H. (2008), La monnaie dans le trueque en Argentine : une approche institutionaliste, Mémoire de Master en science sociale, mention Economie "Etudes comparatives du développement ", Paris, EHESS.

Sagüés, N. (2001), "El retorno de los bonos provinciales", La Nacion, 9 septembre.

Sbatella, J. A. (2004), "Crisis fiscal y rol de la moneda. La experiencia argentina de la década de 1990", in Boyer, R y J. C. Neffa (coord.), La 
economía argentina y su crisis (1976-2001), Buenos Aires, CEILPIETTE et Miño y Dávila, pp. 511-517.

Schuldt, J. (1997). Dineros alternativos para el desarrollo local, Universidad de Pacifico, Perù, pp. 76-82.

Schvarzer, J. et Finkelstein (2003), "Bonos, cuasi monedas y política económica", Realidad Económica, n 193, pp. 79-95.

Servet, J.-M., B. Théret et Z. Yildirim (2008), "Universalité du fait monétaire et pluralité des monnaies ", in Baumann E., Bazin, L., Ould Ahmed P. et alii (dir.), L'Argent des anthropologues, la monnaie des économistes, Paris, L'Harmattan, pp. 167-207.

Sgard, J. (2007), "Hyperinflation et reconstruction de la monnaie nationale: une comparaison de l'Argentine et du Brésil (19902002) ", in B. Théret (dir.), La monnaie dévoilée par ses crises, Paris, Editions de l'EHESS, Vol. 1, pp. 461-487.

Simmel, G. (1987), Philosophie de l'argent, Paris, PUF.

Standard \& Poor's (2001), Las Provincias argentinas en riesgo, Octubre.

Théret, B. (1998), "De la dualité des dettes et de la monnaie dans les sociétés salariales", in La monnaie souveraine, M. Aglietta et A. Orléan (dir.), Paris, Editions Odile Jacob, pp. 253-287.

Théret, B. (2007), "La monnaie au prisme de ses crises d'hier et d'aujourd'hui ", in B. Théret (dir.), La monnaie dévoilée par ses crises, Paris, Editions de l'EHESS, Vol. 1, pp. 17-74.

Théret, B. (2008a), "Les trois états de la monnaie. Approche interdisciplinaire du fait monétaire ", Revue économique, Vol. 59, $\mathrm{n}^{\circ}$ 4, juillet, pp. 813-841.

Théret, B. (2008b), "La souveraineté : des référentiels philosophiques pluriels, des régimes historiques hybrides ", in O. Giraud et $\mathrm{Ph}$. Warin (dir.), Politiques publiques et démocratie, Paris, Editions La Découverte, pp. 381-406.

Théret, B. (dir.) (2007), La monnaie dévoilée par ses crises, Paris. Editions de l'EHESS, 2 vol.

Vilas, C. M. (2001), " Como con bronca y junando .... Las elecciones del 14 de octubre 2001 ", Revista Realidad Económica, n 183, oct.nov.

http:/ / www.iade.org.ar/modules / noticias / article.php?storyid=689

Weiman, D. (ed.) (2006), "The formation of an American monetary union ", n spécial de la Financial History Review, 13(1).

Zanabria, M. (2007), "Les monnaies parallèles d'Etat, un mariage de convenance ", in V. Hernandez, P. Ould-Ahmed, J. Papail et P. Phélinas (dir.), Turbulences monétaires et sociales. L'Amérique latine dans une perspective comparée, Paris, L'Harmattan, pp. 51-73.

66 Economie et Institutions - n 10 et $11-1$ er \& 2e semestre 2007 